\title{
Synthesis of $(S)-(-)$-cucurbitine and conformation of its homopeptides
}

Yuto Yamaberi, ${ }^{1}$ Ryo Eto, ${ }^{1}$ Tomohiro Umeno, ${ }^{1}$ Takuma Kato, ${ }^{2}$ Mitsunobu Doi,,${ }^{2}$ Hidetomo Yokoo, ${ }^{3}$ Makoto Oba,,$^{1,3^{*}}$ Masakazu Tanaka ${ }^{1 *}$

${ }^{1}$ Graduate School of Biomedical Sciences, Nagasaki University, 1-14 Bunkyo-machi, Nagasaki 852-

8521 , Japan

${ }^{2}$ Osaka University of Pharmaceutical Sciences, Osaka 569-1094, Japan

${ }^{3}$ Graduate School of Medical Sciences, Kyoto Prefectural University of Medicine, 1-5

Shimogamohangi-cho, Sakyo-ku, Kyoto 606-0823, Japan 


\section{General Experimental Methodology.}

Optical rotations $[\alpha]^{\mathrm{rt}} \mathrm{D}$ were measured using a $1.0 \mathrm{dm}$ cell. Infrared spectra (IR) were recorded for conventional measurements $\left(\mathrm{KBr}\right.$ or neat) and the solution $\left(\mathrm{CDCl}_{3}\right)$ method using $0.1-\mathrm{mm}$ path length of an $\mathrm{NaCl}$ cell. Circular dichroism (CD) spectra were measured using $1.0 \mathrm{~mm}$ path length cell. ${ }^{1} \mathrm{H}$ NMR spectra were determined at 400, 500, or $600 \mathrm{MHz}$, and ${ }^{13} \mathrm{C}$ NMR spectra were determined at 100 or $125 \mathrm{MHz}$. HRMS (FAB) spectra were taken in the dual-focusing sector field mode, and HRMS (ESI) spectra were measured in the TOF mode.

\section{Synthetic Procedures}

\section{Diethyl 5-Oxo-1-[(R)-1-phenylethyl]pyrrolidine-3,3-dicarboxylate (2)}

$37 \%$ aqueous formaldehyde $(2.99 \mathrm{~mL}, 40.2 \mathrm{mmol})$ was dropwise added to a stirred solution of $(R)$-phenylethylamine $(4.66 \mathrm{~mL}, 36.5 \mathrm{mmol})$ in toluene $(12 \mathrm{~mL})$ at $0{ }^{\circ} \mathrm{C}$. After being stirred at 40 ${ }^{\circ} \mathrm{C}$ using a heating mantle for $3 \mathrm{~h}, 25 \%$ aqueous $\mathrm{NaOH}(150 \mu \mathrm{L})$ was added and the mixture was additionally stirred at $40^{\circ} \mathrm{C}$ using a heating mantle for $1 \mathrm{~h}$. The solution was diluted with water, washed with brine, and dried over $\mathrm{MgSO}_{4}$. Removal of the solvent afforded a crude triazinane $\mathbf{1}$ (quantitative) as a colorless oil, which was used without purification. A solution of crude triazinane 1 (12.2 mmol) and triethyl 1,1,2-ethanetricarboxylate $(2.75 \mathrm{~mL}, 12.2 \mathrm{mmol})$ in trifluoroacetic acid (559 $\mu \mathrm{L}, 2.44 \mathrm{mmol}$ ) was stirred at $100{ }^{\circ} \mathrm{C}$ using a heating mantle for $24 \mathrm{~h}$. The solution was diluted with toluene, washed with $1 \mathrm{M}$ aqueous $\mathrm{HCl}$, water, saturated aqueous $\mathrm{NaHCO}_{3}$, and brine, and dried over $\mathrm{MgSO}_{4}$. After removal of the solvent, the residue was purified by column chromatography on silica gel (30\% EtOAc in $n$-hexane) to give a compound $2(3.58 \mathrm{~g}, 98 \%)$ as a colorless oil. $\quad[\alpha]^{22} \mathrm{D}=$ +43.5 (c 1.12, $\mathrm{CHCl}_{3}$ ); IR (neat) 3470, 3481, 3030, 2982, 2938, 2907, 1738, 1732, 1695, 1450, 1425, $1368,1303,1285,1256,1229,1206,1192,1144,1086,1015 \mathrm{~cm}^{-1} ;{ }^{1} \mathrm{H}$ NMR $\left(400 \mathrm{MHz}, \mathrm{CDCl}_{3}\right) \delta$ 7.27-7.36 (m, 5H), 5.49 (q, $J=7.1 \mathrm{~Hz}, 1 \mathrm{H}), 4.23(\mathrm{q}, J=7.1 \mathrm{~Hz}, 2 \mathrm{H}), 4.08-4.16(\mathrm{~m}, 2 \mathrm{H}), 3.82(\mathrm{~d}, J$ 
$=10 \mathrm{~Hz}, 1 \mathrm{H}), 3.36(\mathrm{~d}, J=10 \mathrm{~Hz}, 1 \mathrm{H}), 3.09(\mathrm{~d}, J=17 \mathrm{~Hz}, 1 \mathrm{H}), 2.97(\mathrm{~d}, J=17 \mathrm{~Hz}, 1 \mathrm{H}), 1.54(\mathrm{~d}, J=$

$7.2 \mathrm{~Hz}, 3 \mathrm{H}), 1.26(\mathrm{t}, J=7.2 \mathrm{~Hz}, 3 \mathrm{H}), 1.56(\mathrm{t}, J=7.1 \mathrm{~Hz}, 3 \mathrm{H}) ;{ }^{13} \mathrm{C} \mathrm{NMR}\left(100 \mathrm{MHz}, \mathrm{CDCl}_{3}\right) \delta 170.1$, $169.3,169.1,139.2,128.4,127.5,126.9,62.2,62.1,52.9,49.0,47.6,38.3,15.8,13.8,13.7$; HRMS (ESI) $\mathrm{m} / \mathrm{z}:[\mathrm{M}+\mathrm{Na}]^{+}$Calcd for $\mathrm{C}_{18} \mathrm{H}_{23} \mathrm{NNaO}_{5}$ 356.1473; Found 356.1474.

\section{(R)-3-Ethoxycarbonyl-5-oxo-1-[(R)-1-phenylethyl]pyrrolidine-3-carboxylic Acid (3)}

A porcine liver esterase (3.4 KU) was added to a stirred solution of 2 (13.9 g, $41.8 \mathrm{mmol})$ in acetone $(100 \mathrm{~mL})$ and $0.05 \mathrm{M}$ phosphate buffer $(\mathrm{pH} 8.0 ; 1880 \mathrm{~mL})$. After being stirred at room temperature for $16 \mathrm{~h}$, the solution was filtered out and acetone was evaporated. The solution was washed with EtOAc, acidified with aqueous $\mathrm{HCl}$, extracted with $\mathrm{CHCl}_{3}$, and dried over $\mathrm{Na}_{2} \mathrm{SO}_{4}$. After removal of solvent, the residue was purified by recrystallization from EtOAc to give a compound $3(8.57 \mathrm{~g}, 67 \%)$ as colorless crystals. M.p. $164{ }^{\circ} \mathrm{C}($ decomp. $) ;[\alpha]^{27} \mathrm{D}=+64.6(c 0.60$, $\mathrm{CHCl}_{3}$ ); IR (KBr) 3428, 3250, 3021, 2999, 2982, 2932, 2913, 2886, 2756, 2550, 2496, 1900, 1740 , 1730, 1721, 1630, 1495, 1427, 1368, 1304, 1265, 1213, 1206, 1143, 1099, $1069 \mathrm{~cm}^{-1} ;{ }^{1} \mathrm{H}$ NMR (400 $\left.\mathrm{MHz}, \mathrm{CDCl}_{3}\right) \delta$ 7.24-7.34 (m, 5H), $5.73($ br s, $1 \mathrm{H}), 5.47(\mathrm{q}, J=7.1 \mathrm{~Hz}, 1 \mathrm{H}), 4.25(\mathrm{q}, J=7.1 \mathrm{~Hz}$, 2H), $3.85(\mathrm{~d}, J=11 \mathrm{~Hz}, 1 \mathrm{H}), 3.41(\mathrm{~d}, J=11 \mathrm{~Hz}, 1 \mathrm{H}), 3.09(\mathrm{q}, J=18 \mathrm{~Hz}, 2 \mathrm{H}), 1.54(\mathrm{~d}, J=7.1 \mathrm{~Hz}$, 3H), 1.27 (t, $J=7.1 \mathrm{~Hz}, 3 \mathrm{H}) ;{ }^{13} \mathrm{C}$ NMR (100 MHz, DMSO-d6) $\delta 170.8,170.0,169.7,140.1,128.6$, 127.5, 126.8, 61.9, 52.7, 48.9, 47.7, 37.9, 16.5, 13.9; HRMS (ESI) m/z: $[\mathrm{M}+\mathrm{H}]^{+}$Calcd for $\mathrm{C}_{16} \mathrm{H}_{20} \mathrm{NO}_{5}$ 306.1341; Found 306.1336.

\section{3-Benzyl 3-Ethyl (S)-5-Oxo-1-[(R)-1-phenylethyl]pyrrolidine-3,3-dicarboxylate (4)}

Benzyl bromide $(4.00 \mathrm{~mL}, 33.7 \mathrm{mmol})$ was added to a stirred solution of $\mathbf{3}$ (9.35 g, $30.6 \mathrm{mmol})$, potassium carbonate $(9.37 \mathrm{~g}, 67.8 \mathrm{mmol})$, and tetrabutylammonium iodide $(1.14 \mathrm{~g}, 3.09 \mathrm{mmol})$ in DMF $(70 \mathrm{~mL})$. After being stirred under an Ar atmosphere at room temperature for $23 \mathrm{~h}$, the 
solution was diluted with water, extracted with EtOAc, washed with water and brine, and dried over $\mathrm{MgSO}_{4}$. After removal of the solvent, the residue was purified by column chromatography on silica gel (30\% EtOAc in $n$-hexane) to give a compound $4\left(12.1 \mathrm{~g}\right.$, quantitative) as a colorless oil. $\quad[\alpha]^{26}$ $=+31.7\left(c 1.00, \mathrm{CHCl}_{3}\right)$; IR (neat) 3483, 2980, 2905, 1958, 1738, 1694, 1497, 1454, 1425, 1368, 1306, 1256, 1180, 1084, 1013 $\mathrm{cm}^{-1} ;{ }^{1} \mathrm{H}$ NMR $\left(400 \mathrm{MHz}, \mathrm{CDCl}_{3}\right) \delta 7.20-7.33(\mathrm{~m}, 10 \mathrm{H}), 5.48(\mathrm{q}, J=$ $7.0 \mathrm{~Hz}, 1 \mathrm{H}), 5.13(\mathrm{~d}, J=12 \mathrm{~Hz}, 1 \mathrm{H}), 5.04(\mathrm{~d}, J=12 \mathrm{~Hz}, 1 \mathrm{H}), 4.14$ (q, $J=7.1 \mathrm{~Hz}, 2 \mathrm{H}), 3.82(\mathrm{~d}, J=$ $11 \mathrm{~Hz}, 1 \mathrm{H}), 3.37(\mathrm{~d}, J=11 \mathrm{~Hz}, 1 \mathrm{H}), 3.11(\mathrm{~d}, J=18 \mathrm{~Hz}, 1 \mathrm{H}), 2.98(\mathrm{~d}, J=17 \mathrm{~Hz}, 1 \mathrm{H}), 1.53(\mathrm{~d}, J=6.9$ $\mathrm{Hz}, 3 \mathrm{H}), 1.14(\mathrm{t}, J=7.0 \mathrm{~Hz}, 3 \mathrm{H}) ;{ }^{13} \mathrm{C} \mathrm{NMR}\left(100 \mathrm{MHz}, \mathrm{CDCl}_{3}\right) \delta 170.1,169.3,169.1,139.3,134.8$, 128.6, 128.2 $127.7,127.0,67.8,62.5,53.1,49.2,47.7,38.5,15.9,13.8 ;$ HRMS (ESI) m/z: $[\mathrm{M}+\mathrm{H}]^{+}$ Calcd for $\mathrm{C}_{23} \mathrm{H}_{26} \mathrm{NO}_{5} 396.1811$; Found 396.1810.

\section{(R)-1-tert-Butoxycarbonyl-3-ethoxycarbonylpyrrolidine-3-carboxylic Acid (5)}

A solution of 9-borabicyclo[3.3.1]nonane in THF $(25.0 \mathrm{~mL}, 12.5 \mathrm{mmol})$ was added to a stirred solution of 4 (1.22 g, $3.09 \mathrm{mmol})$ in THF (6 mL) under an Ar atmosphere and the solution was refluxed using a heating mantle for $2 \mathrm{~h}$. The solution was evaporated and diluted with $\mathrm{Et}_{2} \mathrm{O}$, ethanolamine $(0.751 \mathrm{~mL}, 12.5 \mathrm{mmol})$ was added to the solution. After being stirred at room temperature for $1 \mathrm{~h}$, the solution was filtered through a celite pad and the filtrate was evaporated. The residue was roughly purified by column chromatography on silica gel ( $10 \%$ EtOAc in $n$-hexane) to give a deoxygenated compound (1.09 g) as a colorless oil, which was used without complete purification. A mixture of deoxygenated compound (1.09 g, $2.86 \mathrm{mmol}), 10 \% \mathrm{Pd}-\mathrm{C}$ (261 mg), and $\mathrm{Boc}_{2} \mathrm{O}(1.06 \mathrm{~mL}, 42.8 \mathrm{mmol})$ in THF $(36 \mathrm{~mL})$ was rigorously stirred under an $\mathrm{H}_{2}$ atmosphere at room temperature for $2 \mathrm{~d}$. Then, the mixture was filtered through a celite pad and the filtrate was evaporated. The residue was diluted with $\mathrm{Et}_{2} \mathrm{O}$ and extracted with $2.5 \%$ aqueous $\mathrm{Na}_{2} \mathrm{CO}_{3}$. Aqueous solution was acidified to $\mathrm{pH} 2$ with $1 \mathrm{M}$ aqueous $\mathrm{HCl}$, extracted with $\mathrm{CHCl}_{3}$, and dried over 
$\mathrm{Na}_{2} \mathrm{SO}_{4}$. Removal of the solvent afforded a compound $5(693 \mathrm{mg}, 78 \%$ in 2 steps from 4) as a colorless oil. $[\alpha]^{23} \mathrm{D}=+0.97\left(c 1.55, \mathrm{CHCl}_{3}\right)$ : IR (neat) 3458, 2980, 2936, 2617, 2582, 1738, 1705, 1643, 1479, 1433, 1369, 1260, 1179, 1146, 1069, $1020 \mathrm{~cm}^{-1} ;{ }^{1} \mathrm{H}$ NMR $\left(400 \mathrm{MHz}, \mathrm{CDCl}_{3}\right) \delta 9.95(\mathrm{br}$ s, 1H), $4.24(\mathrm{q}, J=7.1 \mathrm{~Hz}, 2 \mathrm{H}), 3.90(\mathrm{~s}, 1 \mathrm{H}), 3.85(\mathrm{~s}, 1 \mathrm{H}), 3.48(\mathrm{~m}, 2 \mathrm{H}), 2.44(\mathrm{t}, J=7.1 \mathrm{~Hz}, 2 \mathrm{H}), 1.46$ (s, 9H), $1.28(\mathrm{t}, J=7.2 \mathrm{~Hz}, 3 \mathrm{H}) ;{ }^{13} \mathrm{C} \mathrm{NMR}\left(125 \mathrm{MHz}, \mathrm{CDCl}_{3}\right) \delta 173.3,169.6,154.4,80.2,62.2,51.6$, 44.7, 32.3, 29.7, 28.5, 13.9; HRMS (ESI) m/z: $[\mathrm{M}+\mathrm{Na}]^{+}$Calcd for $\mathrm{C}_{13} \mathrm{H}_{21} \mathrm{NNaO}_{6}$ 310.1267; Found 310.1265.

Ethyl (S)-1-tert-Butoxycarbonyl-3-benzyloxycarbonylaminopyrrolidine-3-carboxylate [Cbz(S)-cucurbitine(Boc)-OEt; 6]

A solution of 5 (30.6 mg, $107 \mu \mathrm{mol}$ ) diphenylphosphoryl azide (DPPA; $25.4 \mu \mathrm{L}, 118 \mu \mathrm{mol}$ ), and $\mathrm{Et}_{3} \mathrm{~N}(16.4 \mu \mathrm{L}, 118 \mu \mathrm{mol})$ in toluene $(3 \mathrm{~mL})$ was stirred under $\mathrm{Ar}$ atmosphere at $80^{\circ} \mathrm{C}$ using a heating mantle for $2 \mathrm{~h}$. Then, benzylalcohol $(12.2 \mu \mathrm{L}, 118 \mu \mathrm{mol})$ was added to the stirred solution, and the solution was stirred at $80^{\circ} \mathrm{C}$ using a heating mantle for $12 \mathrm{~h}$. The solution was diluted with toluene, washed with brine, and dried over $\mathrm{Na}_{2} \mathrm{SO}_{4}$. After removal of the solvent, the residue was purified by column chromatography on silica gel (30\% EtOAc in $n$-hexane) to give a compound 6 (30.1 mg, $72 \%)$ as a colorless oil. $[\alpha]^{21} \mathrm{D}=+7.74\left(c 1.24, \mathrm{CHCl}_{3}\right)$; IR (neat) 3319, 2978, 2895, 2139, 1740, $1699,1674,1525,1406,1368,1254,1175,1140,1090,1055,1028 \mathrm{~cm}^{-1} ;{ }^{1} \mathrm{H} \mathrm{NMR}\left(400 \mathrm{MHz}, \mathrm{CDCl}_{3}\right)$ ઈ 7.26-7.42 (m, 5H), 5.30 (br s, 1H), 5.03-5.18 (m, 2H), $4.20(\mathrm{~m}, 2 \mathrm{H}), 3.79-3.89(\mathrm{~m}, 1 \mathrm{H}), 3.63-$ $3.66(\mathrm{~m}, 1 \mathrm{H}), 3.45-3.57(\mathrm{~m}, 2 \mathrm{H}), 2.24-2.45(\mathrm{~m}, 2 \mathrm{H}), 1.45(\mathrm{~s}, 9 \mathrm{H}), 1.22-1.29(\mathrm{~m}, 3 \mathrm{H}) ;{ }^{13} \mathrm{C} \mathrm{NMR}(125$ $\mathrm{MHz}, \mathrm{CDCl}_{3}$ ) mixture of rotamers $\delta 171.4,155.4,154.2,136.2,128.4,128.1,128.0,79.7,66.9,64.4$ and 63.4, 61.8, 54.5, 44.4 and 44.0, 34.5, 28.4, 13.9: HRMS (ESI) m/z: $[\mathrm{M}+\mathrm{Na}]^{+}$Calcd for $\mathrm{C}_{20} \mathrm{H}_{28} \mathrm{~N}_{2} \mathrm{NaO}_{6} 415.1845 ;$ Found 415.1855. 


\section{Dipeptide; Cbz-[(S)-cucurbitine(Boc) $]_{2}$-OEt (9)}

A solution of $6(86.7 \mathrm{mg}, 221 \mu \mathrm{mol})$ in $\mathrm{EtOH}(4 \mathrm{~mL})$ and $1 \mathrm{M}$ aqueous $\mathrm{NaOH}(884 \mu \mathrm{L})$ was stirred at room temperature for $19 \mathrm{~h}$. The solution was evaporated, diluted with water, acidified with $1 \mathrm{M}$ aqueous $\mathrm{HCl}$, extracted with $\mathrm{CHCl}_{3}$, and dried over $\mathrm{Na}_{2} \mathrm{SO}_{4}$. Removal of the solvent gave a crude carboxylic acid 7 (88.3 mg, quantitative) as a colorless oil, which was used without purification. A mixture of $6(48.8 \mathrm{mg}, 124 \mu \mathrm{mol})$ and $5 \% \mathrm{Pd}-\mathrm{C}(26.9 \mathrm{mg})$ in EtOH $(4 \mathrm{~mL})$ was rigorously stirred under an $\mathrm{H}_{2}$ atmosphere at room temperature for $21 \mathrm{~h}$. Then, the mixture was filtered through a celite pad and the filtrate was evaporated to give a crude amine 8 (36.9 $\mathrm{mg}$, quantitative) as colorless crystals, which was used without purification. A solution of 7 (42.8 mg, $117 \mu \mathrm{mol}), 8(29.1 \mathrm{mg}, 113$ $\mu \mathrm{mol})$, COMU (50.1 mg, $117 \mu \mathrm{mol})$, and ${ }^{i} \operatorname{Pr}_{2} \operatorname{EtN}(40.1 \mu \mathrm{L}, 234 \mu \mathrm{mol})$ in DMF (3 mL) was stirred under an Ar atmosphere at $40{ }^{\circ} \mathrm{C}$ using a heating mantle for $2 \mathrm{~d}$. The solution was diluted with EtOAc, washed with saturated aqueous $\mathrm{NaHCO}_{3}$ and brine, and dried over $\mathrm{MgSO}_{4}$. After removal of the solvent, the residue was purified by column chromatography on silica gel $(70 \%$ EtOAc in $n$ hexane) to give a dipeptide $9(44.3 \mathrm{mg}, 65 \%)$ as colorless crystals. M.p. $117-119{ }^{\circ} \mathrm{C} ;[\alpha]^{17} \mathrm{D}=+0.89$ (c 1.0, $\mathrm{CHCl}_{3}$ ); IR (KBr) 3377, 3300, 2978, 2934, 2903, 1692, 1667, 1535, 1479, 1450, 1400, 1368, 1312, 1287, 1252, 1177, 1144, 1109, $1070 \mathrm{~cm}^{-1} ;{ }^{1} \mathrm{H}$ NMR (500 MHz, CD $\left.{ }_{3} \mathrm{CN}\right) \delta$ 7.38-7.39 (m, 4H), 7.33-7.35 (m, 1H), 7.26 (br s, 1H), 6.10 (br s, 1H), 5.05-5.14 (m, 2H), $4.12(\mathrm{q}, J=5.6 \mathrm{~Hz}, 2 \mathrm{H}), 3.78-$ $3.80(\mathrm{~m}, 2 \mathrm{H}), 3.54(\mathrm{~d}, J=9.2 \mathrm{~Hz}, 1 \mathrm{H}), 3.36-3.47(\mathrm{~m}, 5 \mathrm{H}), 2.25-2.45(\mathrm{~m}, 2 \mathrm{H}), 2.11-2.15(\mathrm{~m}, 2 \mathrm{H})$, $1.45(\mathrm{~s}, 9 \mathrm{H}), 1.33(\mathrm{~s}, 9 \mathrm{H}), 1.21(\mathrm{t}, J=5.6 \mathrm{~Hz}, 3 \mathrm{H}) ;{ }^{13} \mathrm{C} \mathrm{NMR}\left(125 \mathrm{MHz}, \mathrm{CD}_{3} \mathrm{CN}\right) \delta 172.9,172.5$, $156.9,155.45,155.39,138.3,129.8,129.3,129.2,80.3,79.4,67.9,62.6,55.2,45.3,35.3,29.1,14.7$; HRMS (ESI) m/z: [M + Na $]^{+}$Calcd for $\mathrm{C}_{30} \mathrm{H}_{44} \mathrm{~N}_{4} \mathrm{NaO}_{9}$ 627.3006; Found 627.3019.

\section{Tripeptide; Cbz-[(S)-cucurbitine(Boc) $]_{3}$-OEt (10)}

A mixture of 9 (1.09 g, $1.80 \mathrm{mmol})$ and 5\% Pd-C (412 mg) in EtOH was rigorously stirred under an 
$\mathrm{H}_{2}$ atmosphere at room temperature for $15 \mathrm{~h}$. Then, the mixture was filtered through a celite pad and the filtrate was evaporated to give a crude amine, which was dissolved in DMF (15 mL), The carboxylic acid 7 (705 mg, $1.94 \mathrm{mmol})$, COMU (836 mg, $1.95 \mathrm{mmol})$, and ${ }^{i} \operatorname{Pr}_{2} \operatorname{EtN}(663 \mu \mathrm{L}, 3.87$ mmol) were added to the amine solution, and the solution was stirred at $40{ }^{\circ} \mathrm{C}$ using a heating mantle for $2 \mathrm{~d}$. The solution was diluted with EtOAc, washed with saturated aqueous $\mathrm{NaHCO}_{3}$ and brine, and dried over $\mathrm{MgSO}_{4}$. After removal of the solvent, the residue was purified by column chromatography on silica gel (70\% EtOAc in $n$-hexane) to give a tripeptide $\mathbf{1 0}(1.21 \mathrm{~g}, 83 \%)$ as colorless crystals. $\quad$ M.p. $117-118^{\circ} \mathrm{C} ;[\alpha]^{17} \mathrm{D}=+0.91\left(c\right.$ 1.0, $\left.\mathrm{CHCl}_{3}\right)$; IR $(\mathrm{KBr}) 3327,3310,3294$, 2978, 2934, 2893, 1692, 1530, 1479, 1408, 1256, 1175, 1142, $1107 \mathrm{~cm}^{-1} ;{ }^{1} \mathrm{H}$ NMR (500 MHz, $\left.\mathrm{CD}_{3} \mathrm{CN}\right) \delta 7.50$ (br s, 1H), 7.40-7.41 (m, 4H), 7.35-7.36 (m, 1H), 7.17 (br s, 1H), 6.43 (br s, 1H), 5.14-5.21 (m, 2H), $4.12(\mathrm{q}, J=5.6 \mathrm{~Hz}, 2 \mathrm{H}), 3.68-3.92(\mathrm{~m}, 3 \mathrm{H}), 3.39-3.51(\mathrm{~m}, 9 \mathrm{H}), 2.29-2.31(\mathrm{~m}$, 3H), 2.19-2.20 (m, 1H), 2.06-2.10 (m, 2H), $1.45(\mathrm{~s}, 18 \mathrm{H}), 1.44(\mathrm{~s}, 9 \mathrm{H}), 1.22(\mathrm{t}, J=5.6 \mathrm{~Hz}, 3 \mathrm{H}) ;{ }^{13} \mathrm{C}$ NMR (125 MHz, CD $\left.{ }_{3} \mathrm{CN}\right) \delta 172.7,172.6,172.5,158.0,155.5,155.4,138.2,129.9,129.4,128.9$, 80.3, 80.2, 80.1, 79.4, 68.3, 62.4, 55.4, 55.21, 55.15, 45.4, 35.7, 35.2, 29.1, 14.8; HRMS (ESI) m/z: $[\mathrm{M}+\mathrm{Na}]^{+}$Calcd for $\mathrm{C}_{40} \mathrm{H}_{60} \mathrm{~N}_{6} \mathrm{NaO}_{12}$ 839.4167; Found 839.4182.

\section{Tetrapeptide; Cbz-[(S)-cucurbitine(Boc) $]_{4}$-OEt (11)}

Tetrapeptide 11 was prepared from $10(1.22 \mathrm{~g}, 1.49 \mathrm{mmol})$ in a similar manner to that described for the preparation of $\mathbf{1 0}(1.45 \mathrm{~g}, 95 \%)$ as colorless crystals. M.p. $147-148{ }^{\circ} \mathrm{C} ;[\alpha]^{17} \mathrm{D}=+2.37(c 1.0$, $\left.\mathrm{CHCl}_{3}\right)$; IR (KBr) 3329, 2978, 2934, 2895, 1692, 1530, 1479, 1402, 1366, 1258, 1175, 1140, 1107 $\mathrm{cm}^{-1} ;{ }^{1} \mathrm{H}$ NMR (500 MHz, CD $\left.{ }_{3} \mathrm{CN}\right) \delta 7.55$ (br s, 1H), 7.46 (br s, 2H), 7.39-7.46 (m, 4H), 7.34-7.36 (m, 1H), 6.63 (br s, 1H), 5.14-5.21 (m, 2H), 4.12 (q, $J=5.6 \mathrm{~Hz}, 2 \mathrm{H}), 3.75-3.95(\mathrm{~m}, 4 \mathrm{H}), 3.34-3.60$ (m, 12H), 2.12-2.31 (m, 8H), $1.448(\mathrm{~s}, 9 \mathrm{H}), 1.440(\mathrm{~s}, 9 \mathrm{H}), 1.43(\mathrm{~s}, 9 \mathrm{H}), 1.42(\mathrm{~s}, 9 \mathrm{H}), 1.22(\mathrm{t}, J=5.6$ $\mathrm{Hz}, 3 \mathrm{H}) ;{ }^{13} \mathrm{C} \mathrm{NMR}\left(125 \mathrm{MHz}, \mathrm{CD}_{3} \mathrm{CN}\right) \delta 174.6,173.2,172.5,172.2,158.4,155.4,155.3,138.0$, 
$130.1,129.7,129.3,129.0,128.7,80.4,80.3,80.0,79.2,68.5,62.4,55.4,55.3,55.14,55.06,55.0$, 54.8, 45.4, 45.3, 35.9, 29.3, 29.20, 29.17, 29.1, 28.9, 14.9; HRMS (ESI) m/z: $[\mathrm{M}+\mathrm{Na}]^{+}$Calcd for $\mathrm{C}_{50} \mathrm{H}_{76} \mathrm{~N}_{8} \mathrm{NaO}_{15}$ 1051.5328; Found 1051.5304.

\section{Pentapeptide; Cbz-[(S)-cucurbitine(Boc) $]_{5}$-OEt (12)}

Pentapeptide 12 was prepared from 11 (1.59 g, $1.54 \mathrm{mmol})$ in a similar manner to that described for the preparation of $\mathbf{1 0}(1.16 \mathrm{~g}, 61 \%)$ as colorless crystals. M.p. $166-168^{\circ} \mathrm{C} ;[\alpha]^{17} \mathrm{D}=+1.60(\mathrm{c} 1.0$, $\mathrm{CHCl}_{3}$ ); IR (KBr) 3327, 3314, 2978, 2934, 2891, 1692, 1657, 1535, 1408, 1256, 1175, $1138 \mathrm{~cm}^{-1} ;{ }^{1} \mathrm{H}$ NMR (500 MHz, CD 3 CN) $\delta 7.67$ (br s, 1H), 7.64 (br s, 1H), 7.45 (br s, 1H), 7.35-7.41 (m, 6H), 6.69 (br s, 1H), $5.20(\mathrm{~d}, J=10 \mathrm{~Hz}, 1 \mathrm{H}), 5.15(\mathrm{~d}, J=9.6 \mathrm{~Hz}, 1 \mathrm{H}), 4.12(\mathrm{q}, J=2.7 \mathrm{~Hz}, 2 \mathrm{H}), 3.97(\mathrm{~d}, J=8.8$ $\mathrm{Hz}, 2 \mathrm{H}), 3.68-3.87(\mathrm{~m}, 3 \mathrm{H}), 3.40-3.61(\mathrm{~m}, 15 \mathrm{H}), 2.17-2.32(\mathrm{~m}, 10 \mathrm{H}), 1.43-1.44(\mathrm{~m}, 45 \mathrm{H}), 1.22(\mathrm{t}$, $J=5.6 \mathrm{~Hz}, 3 \mathrm{H}) ;{ }^{13} \mathrm{C} \mathrm{NMR}\left(125 \mathrm{MHz}, \mathrm{CD}_{3} \mathrm{CN}\right) \delta 175.1,174.2,173.1,172.7,172.5,158.5,155.6$, $155.4,155.3,137.9,129.9,129.5,128.8,80.4,80.2,80.1,79.4,68.6,62.4,55.1,55.0,54.9,54.5,45.6$, 45.5, 45.3, 45.1, 36.0, 35.8, 29.2, 29.1, 14.8; HRMS (ESI) m/z: $[\mathrm{M}+\mathrm{Na}]^{+}$Calcd for $\mathrm{C}_{60} \mathrm{H}_{92} \mathrm{~N}_{10} \mathrm{NaO}_{18}$ 1263.6489; Found 1263.6477.

\section{Hexapeptide; Cbz-[(S)-cucurbitine(Boc) $]_{6}-$ OEt (13)}

Hexapeptide 13 was prepared from $12(1.08 \mathrm{~g}, 0.869 \mathrm{mmol})$ in a similar manner to that described for the preparation of $\mathbf{1 0}(1.07 \mathrm{~g}, 85 \%)$ as colorless crystals. M.p. $183-184{ }^{\circ} \mathrm{C} ;[\alpha]^{17} \mathrm{D}=+1.94(c 1.0$, $\mathrm{CHCl}_{3}$ ); IR (KBr) 3329, 3313, 2978, 2936, 2889, 2374, 1697, 1535, 1408, 1260, 1175, $1140 \mathrm{~cm}^{-1} ;{ }^{1} \mathrm{H}$ NMR (500 MHz, CD 3 CN) $\delta 7.71$ (br s, 1H), 7.59 (br s, 2H), 7.46 (br s, 1H), 7.37-7.41 (m, 6H), 6.73 (br s, 1H), $5.22(\mathrm{~d}, J=10 \mathrm{~Hz}, 1 \mathrm{H}), 5.13(\mathrm{~d}, J=10 \mathrm{~Hz}, 1 \mathrm{H}), 4.13(\mathrm{q}, J=2.5 \mathrm{~Hz}, 2 \mathrm{H}), 3.39-3.77$ (m, 24H), 2.19-2.34 (m, 12H), 1.43-1.46 (m, 54H), $1.23(\mathrm{t}, J=5.6 \mathrm{~Hz}, 3 \mathrm{H}) ;{ }^{13} \mathrm{C}$ NMR $(125 \mathrm{MHz}$, $\left.\mathrm{CD}_{3} \mathrm{CN}\right) \delta 174.5,173.2,172.5,158.5,155.5,155.4,155.34,155.31,137.8,130.0,129.5,128.9,80.41$, 
$80.39,80.3,80.2,80.0,79.4,68.7,62.4,55.1,54.8,54.5,54.3,45.6,45.3,45.1,35.8,29.1,14.8$; HRMS (ESI) m/z: [M + Na $]^{+}$Calcd for $\mathrm{C}_{70} \mathrm{H}_{108} \mathrm{~N}_{12} \mathrm{NaO}_{21}$ 1475.7650; Found 1475.7631.

\section{Heptapeptide; Cbz-[(S)-cucurbitine(Boc)]7-OEt (14)}

Heptapeptide 14 was prepared from $13(991 \mathrm{mg}, 0.682 \mathrm{mmol})$ in a similar manner to that described for the preparation of $\mathbf{1 0}(863 \mathrm{mg}, 76 \%)$ as colorless crystals. $\quad$ M.p. $172-173{ }^{\circ} \mathrm{C} ;[\alpha]^{17} \mathrm{D}=+2.94(\mathrm{c}$ 1.0, $\mathrm{CHCl}_{3}$ ); IR (KBr) 3335, 2978, 2933, 1697, 1528, 1406, 1367, 1258, 1175, $1140 \mathrm{~cm}^{-1}$; ${ }^{1} \mathrm{H} \mathrm{NMR}$ (500 MHz, CD $\left.{ }_{3} \mathrm{CN}\right) \delta 7.77$ (br s, $\left.1 \mathrm{H}\right), 7.67$ (br s, 2H), 7.47 (br s, 1H), 7.35-7.41 (m, 7H), 6.96 (br s, $1 \mathrm{H}), 5.26(\mathrm{~d}, J=10 \mathrm{~Hz}, 1 \mathrm{H}), 5.12(\mathrm{~d}, J=9.6 \mathrm{~Hz}, 1 \mathrm{H}), 3.40-4.14(\mathrm{~m}, 30 \mathrm{H}), 2.16-2.41(\mathrm{~m}, 14 \mathrm{H})$, $1.43-1.44(\mathrm{~m}, 63 \mathrm{H}), 1.24(\mathrm{t}, J=5.6 \mathrm{~Hz}, 3 \mathrm{H}) ;{ }^{13} \mathrm{C} \mathrm{NMR}\left(125 \mathrm{MHz}, \mathrm{CD}_{3} \mathrm{CN}\right) \delta 174.2,173.0,172.4$, $158.4,155.3,155.1,137.5,129.8,129.6,129.4,129.1,128.9,80.3,80.14,80.06,80.0,79.9,79.8$, 79.4, 68.7, 62.3, 55.0, 54.6, 54.1, 53.9, 45.4, 44.9, 35.7, 29.3, 29.2, 14.8; HRMS (ESI) m/z: [M + $\mathrm{Na}]^{+}$Calcd for $\mathrm{C}_{80} \mathrm{H}_{124} \mathrm{~N}_{14} \mathrm{NaO}_{24}$ 1687.8811; Found 1687.8803.

\section{Octapeptide; Cbz-[(S)-cucurbitine(Boc)] 8 -OEt (15)}

Octapeptide 15 was prepared from $14(829 \mathrm{mg}, 0.492 \mathrm{mmol})$ in a similar manner to that described for the preparation of $\mathbf{1 0}(138 \mathrm{mg}, 15 \%)$ colorless crystals. M.p. $186-188^{\circ} \mathrm{C} ;[\alpha]^{17} \mathrm{D}=-1.44(c 1.0$, $\mathrm{CHCl}_{3}$ ); IR (KBr) 3329, 2978, 2934, 2901, 2374, 1692, 1535, 1479, 1450, 1408, 1368, 1258, 1175 , $1140 \mathrm{~cm}^{-1} ;{ }^{1} \mathrm{H}$ NMR $\left(500 \mathrm{MHz}, \mathrm{CD}_{3} \mathrm{CN}\right) \delta 7.53-7.85(\mathrm{~m}, 4 \mathrm{H}), 7.36-7.41(\mathrm{~m}, 8 \mathrm{H}), 6.84$ (br s, 1H), 5.23-5.30 (m, 1H), 5.08-5.10 (m, 1H), 3.40-4.25 (m, 34H), 1.95-2.41 (m, 16H), $1.42(\mathrm{~s}, 72 \mathrm{H}), 1.23-$ $1.25(\mathrm{~m}, 3 \mathrm{H}) ;{ }^{13} \mathrm{C}$ NMR $\left(125 \mathrm{MHz}, \mathrm{CD}_{3} \mathrm{CN}\right) \delta 174.5,173.2,172.4,158.4,156.34,156.27,155.4$, $137.0,130.0,129.8,129.6,129.3,129.2,80.4,80.2,80.0,68.9,62.4,54.7,45.5,45.0,29.21,29.16$, 14.8; HRMS (ESI) m/z: [M + Na] ${ }^{+}$Calcd for $\mathrm{C}_{90} \mathrm{H}_{140} \mathrm{~N}_{16} \mathrm{NaO}_{27}$ 1899.9972; Found 1899.9971. 


\section{Heptapeptide hydrochloride; $\mathrm{Cbz}-[(S) \text {-cucurbitine } \cdot \mathrm{HCl}]_{7}-\mathrm{OEt}(16)$}

A solution of $14(11.7 \mathrm{mg}, 7.02 \mu \mathrm{mol})$ in $4 \mathrm{M} \mathrm{HCl} /$ dioxane $(700 \mu \mathrm{L})$ was stirred at room temperature for $14 \mathrm{~h}$. Then, the solution was evaporated to give $\mathbf{1 6}(8.6 \mathrm{mg}$, quantitative) as colorless crystals. ${ }^{1} \mathrm{H}$ NMR $\left(500 \mathrm{MHz}, \mathrm{CD}_{3} \mathrm{OH}\right) \delta 9.55$ (br s, 1H), 9.37 (br s, 1H), 9.19 (br s, 7H), 8.44 (br s, $\left.1 \mathrm{H}\right), 8.34$ (br s, 1H), 8.25 (br s, 1H), 7.87 (br s, 1H), 7.43 (br s, 1H), 7.27-7.48 (m, 5H), 5.38 (d, J=12 Hz, $1 \mathrm{H}), 5.21(\mathrm{~d}, J=12 \mathrm{~Hz}, 1 \mathrm{H}), 4.20-4.27(\mathrm{~m}, 2 \mathrm{H}), 3.27-4.04(\mathrm{~m}, 28 \mathrm{H}), 1.94-2.78(\mathrm{~m}, 14 \mathrm{H}), 1.29(\mathrm{t}, J$ $=6.8 \mathrm{~Hz}, 3 \mathrm{H}) ;{ }^{13} \mathrm{C} \mathrm{NMR}\left(125 \mathrm{MHz}, \mathrm{CD}_{3} \mathrm{OD}\right) \delta 175.5,174.63,174.58,174.2,173.7,172.9,171.3$, $158.9,137.2,129.6,129.5,129.23,129.17,73.6,69.6,66.2,66.0,65.73,63.65,54.0,53.9,53.2,52.9$, 52.7, 46.1, 45.8, 45.7, 37.1, 36.3, 36.0, 35.9, 35.3, 14.4; HRMS (ESI) m/z: $[\mathrm{M}-7 \mathrm{HCl}+\mathrm{H}]^{+}$Calcd for $\mathrm{C}_{45} \mathrm{H}_{69} \mathrm{~N}_{14} \mathrm{O}_{10} 965.5321$; Found 965.5319.

\section{Heptapeptide; Cbz-[(S)-cucurbitine $]_{7}-$ OEt (17)}

A mixture of $16(8.6 \mathrm{mg}, 7.02 \mu \mathrm{mol})$ in saturated aqueous $\mathrm{NaHCO}_{3}(351 \mu \mathrm{L})$ and $\mathrm{EtOH}(351 \mu \mathrm{L})$ was stirred at room temperature for $5 \mathrm{~min}$. The solution was evaporated and filtered through a celite pad. The filtrate was evaporated to give $17(5.6 \mathrm{mg}, 83 \%)$ as colorless crystals. ${ }^{1} \mathrm{H}$ NMR (500 MHz, $\left.\mathrm{CD}_{3} \mathrm{OD}\right) \delta 7.67$ (br s, $\left.1 \mathrm{H}\right), 7.62$ (br s, $\left.1 \mathrm{H}\right), 7.58$ (br s, $\left.1 \mathrm{H}\right), 7.50$ (br s, $\left.1 \mathrm{H}\right), 7.43$ (br s, 1H), 7.25-7.31 (m, 5H), 7.20 (br s, 1H), 7.19 (br s, 1H), $4.56(\mathrm{~s}, 2 \mathrm{H}), 4.09-4.18(\mathrm{~m}, 2 \mathrm{H}), 3.27-3.67$ (m, 28H), 2.95 (br s, 7H), 1.40-2.40 (m, 14H), $1.14(\mathrm{t}, J=7.0 \mathrm{~Hz}, 3 \mathrm{H}) ;{ }^{13} \mathrm{C} \mathrm{NMR}\left(125 \mathrm{MHz}, \mathrm{CD}_{3} \mathrm{OD}\right) \delta 174.0,170.6$, $169.6,161.4,132.54,132.47,130.0,129.4,128.3,128.1,69.5,65.7,65.4,64.4,52.9,52.7,52.5,52.3$, 40.4, 39.3, 33.1, 31.8, 31.5, 30.8, 30.7, 30.4, 30.2, 14.4; HRMS (ESI) m/z: $[\mathrm{M}+\mathrm{Na}]^{+}$Calcd for $\mathrm{C}_{45} \mathrm{H}_{68} \mathrm{~N}_{14} \mathrm{NaO}_{10}$ 987.5141; Found 987.5137.

\section{X-ray analysis.}

Single crystals suitable for X-ray diffraction were obtained by slow evaporation from a solution 
of EtOH/ $\mathrm{CHCl}_{3}(1: 1)$ mixture. X-ray diffraction data was collected on a CrystalClear-SM Expert 2.0 r16 (Rigaku, 2014) with a Rigaku Saturn724+ $(4 \times 4$ bin mode $)$ CCD detector using MoK $\alpha(\lambda=$ $0.71073 \AA$ ). The structure was solved by direct methods using SHELXS (Sheldrick, 2008) and refined by full-matrix least-squares methods based F2 using SHELXL-2016/6 (Sheldrick, 2016). The O-bound $\mathrm{H}$ atom was constrained to refine on the parent $\mathrm{O}$ atom with $\mathrm{U}_{\text {iso }}(\mathrm{H})=1.5 \mathrm{Ueq}(\mathrm{O})$, while the other $\mathrm{H}$ atoms were placed in geometrically idealized positions $(\mathrm{C}-\mathrm{H}=0.95-1.00 \AA)$ and refined as riding on their parent atoms, with $\mathrm{U}_{\mathrm{iso}}(\mathrm{H})=1.2 \mathrm{U}_{\mathrm{eq}}(\mathrm{C})$ (or $1.5 \mathrm{U}_{\mathrm{eq}}(\mathrm{C})$ for the methyl groups). 
Table S1. Crystal and diffraction parameters of 3 .

\begin{tabular}{ll}
\hline empirical formula & $\mathrm{C}_{16} \mathrm{H}_{19} \mathrm{NO}_{5}$ \\
formula weight & 305.32 \\
crystal diameters $[\mathrm{mm}]$ & $0.24 \times 0.12 \times 0.06$ \\
crystal system & monoclinic \\
lattice parameters: & \\
$\quad a, b, c[\AA]$ & $7.103,11.956,8.942$ \\
$\quad \alpha, \beta, \gamma\left[{ }^{\circ}\right]$ & $90,95.620,90$ \\
$\quad V\left[\AA^{3}\right]$ & 755.7 \\
space group & $P 21$ \\
$Z$ value & 2 \\
$D$ calc $\left[\mathrm{g} / \mathrm{cm}^{3}\right]$ & 1.342 \\
$\mu($ MoK $\alpha)\left[\mathrm{cm}^{-1}\right]$ & 0.100 \\
no. of observations & $2477(I>2 \sigma(I))$ \\
no. of variables & 202 \\
$R_{l}, R_{w}$ & $0.0455,0.1113$ \\
Solvent & $\mathrm{MeOH} / \mathrm{CHCl}_{3}$ \\
\hline
\end{tabular}




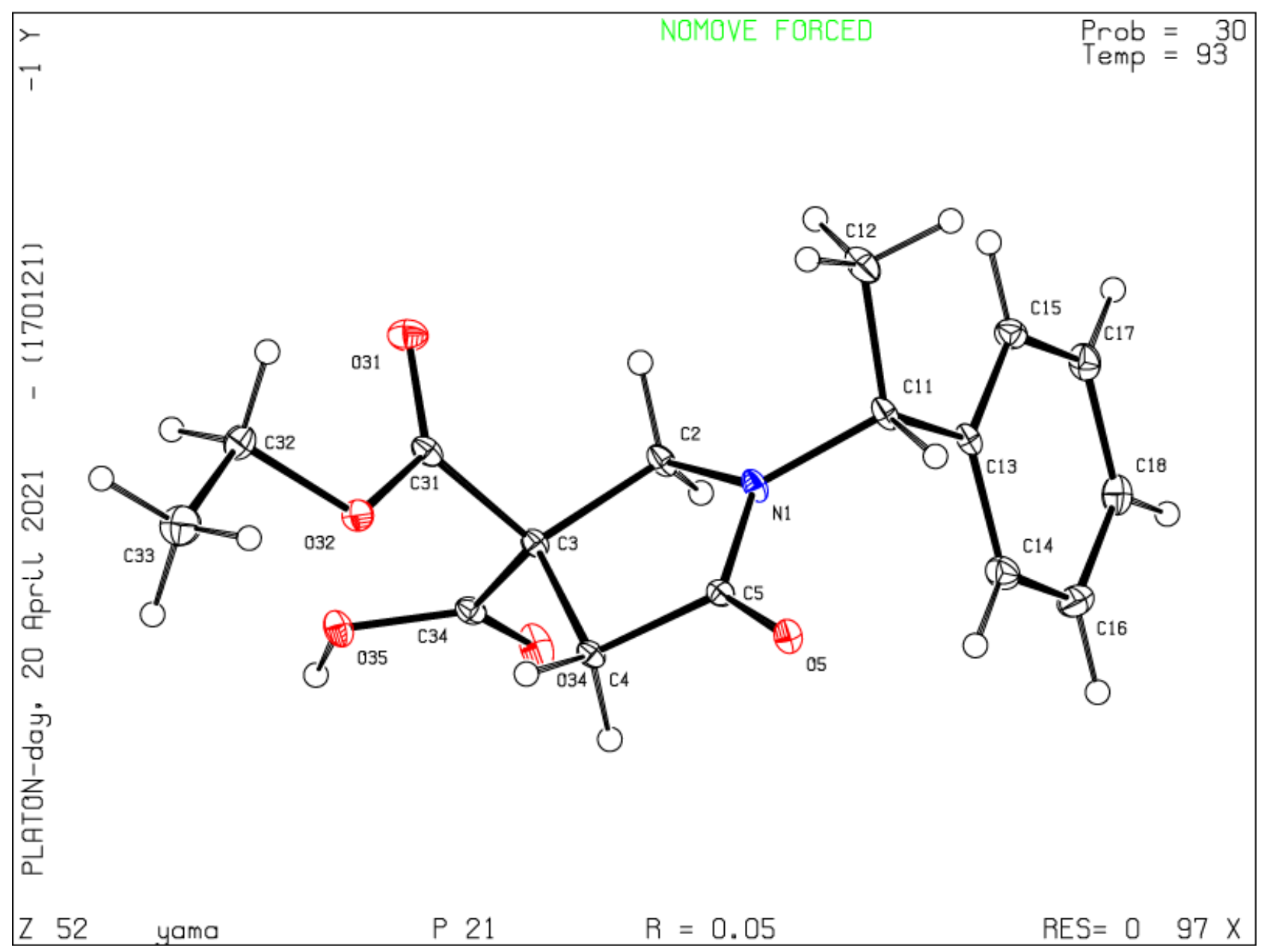

Figure S1. X-ray crystallographic structure of 3. Thermal ellipsoids are drawn at the $30 \%$ probability level and $\mathrm{H}$ atoms are shown as small spheres of arbitrary radii. 

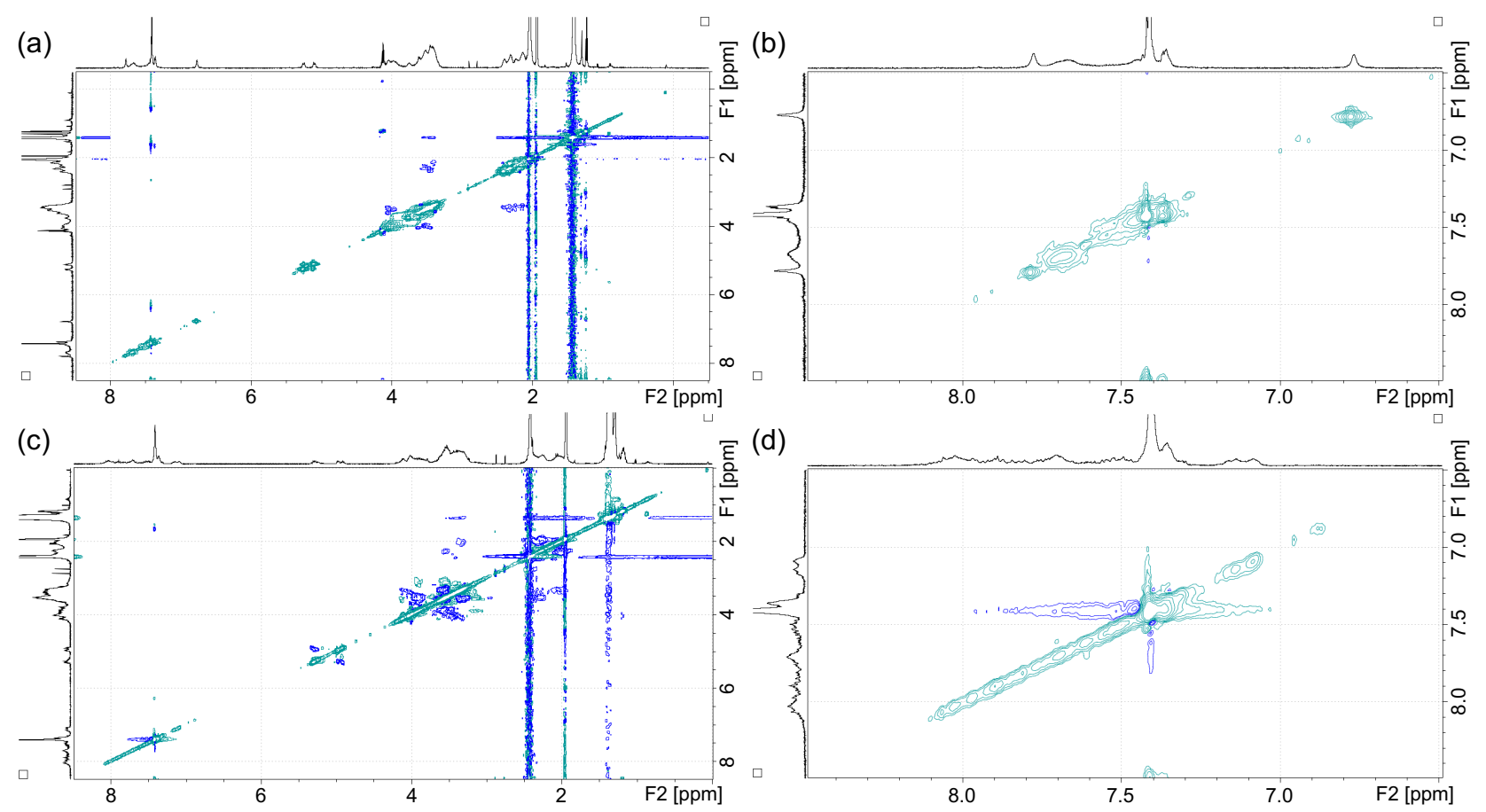

Figure S2. The ROESY NMR spectra of Boc-protected heptapeptide 14 at $60{ }^{\circ} \mathrm{C}(\mathrm{a}, \mathrm{b})$ and $-25^{\circ} \mathrm{C}$ (c, d) in $\mathrm{CD}_{3} \mathrm{CN}(600 \mathrm{MHz})$. (a, c) Full scale and (b, d) NH region. 


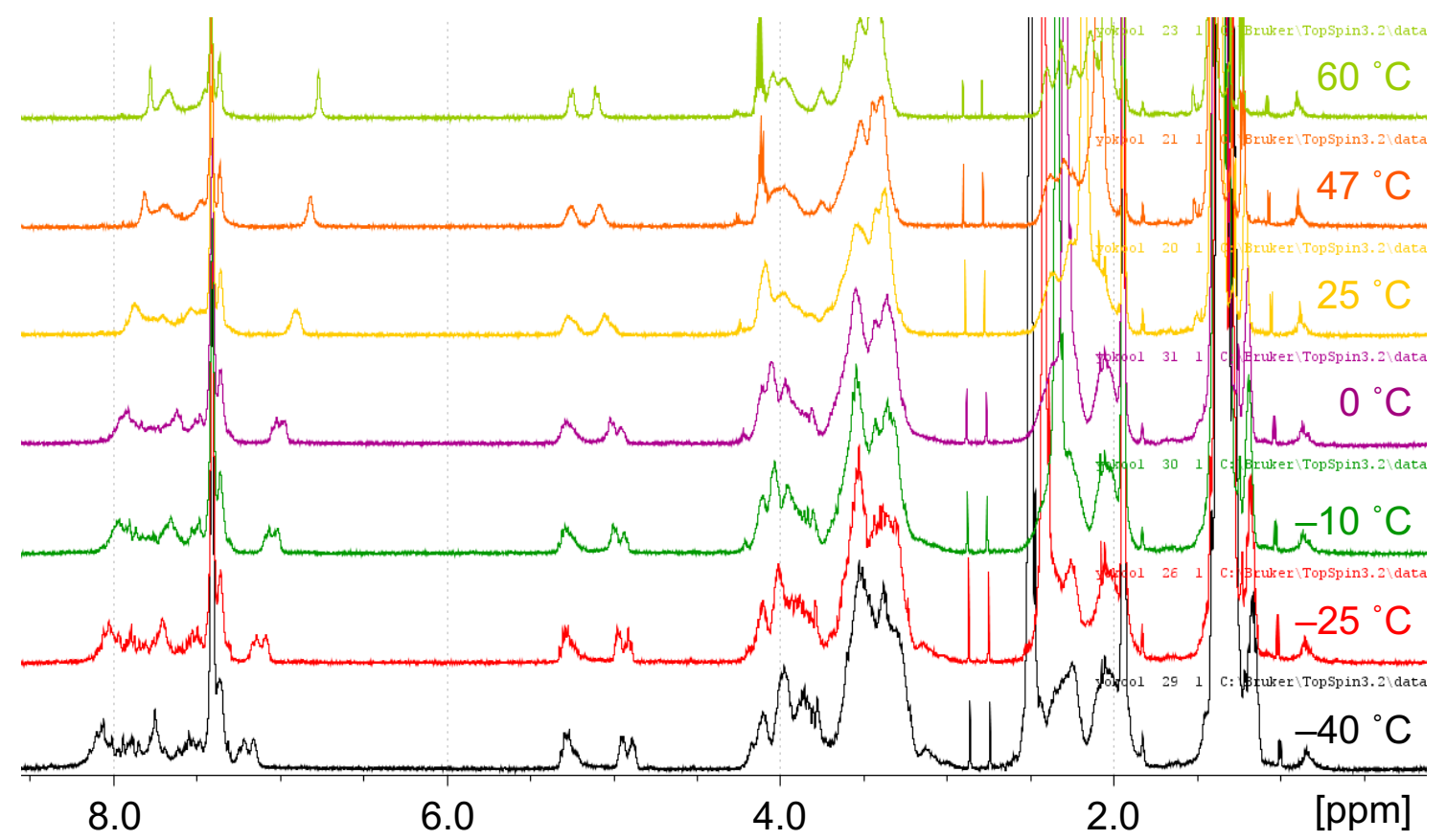

Figure S3. ${ }^{1} \mathrm{H}$ NMR spectra (full scale) of Boc-protected heptapeptide 14 at seven different temperatures $\left(60\right.$ to $\left.-40^{\circ} \mathrm{C}\right)$ in $\mathrm{CD}_{3} \mathrm{CN}(600 \mathrm{MHz})$. 


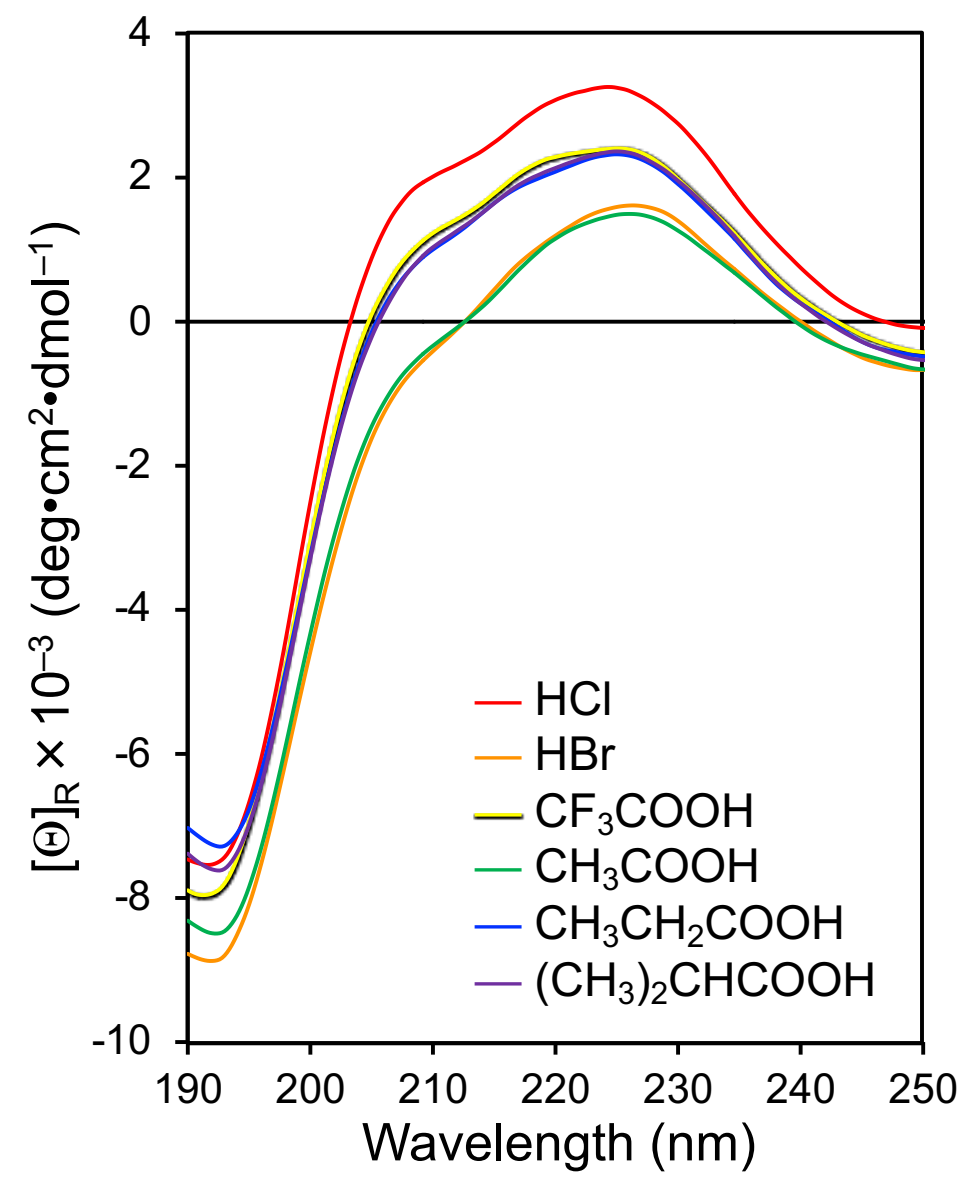

Figure S4. CD spectra of $\mathrm{Cbz}-[(S)$-cucurbitine $] 7-\mathrm{OEt} \mathbf{1 7}$ in aqueous solution with various acids (10 $\mathrm{mM})$. Peptide concentration: $0.1 \mathrm{mM}$. 
${ }^{1} \mathrm{H}$ NMR spectrum of $2\left(400 \mathrm{MHz}\right.$ in $\left.\mathrm{CDCl}_{3}\right)$<smiles>CCOC(=O)C1(C(=O)OCC)CC(=O)N([C@@H](C)c2ccccc2)C1</smiles>

$\underset{\text { is }}{\stackrel{5}{5}}$

$$
\mathrm{EtO}_{2} \mathrm{CO}_{2} \mathrm{Et}
$$

is
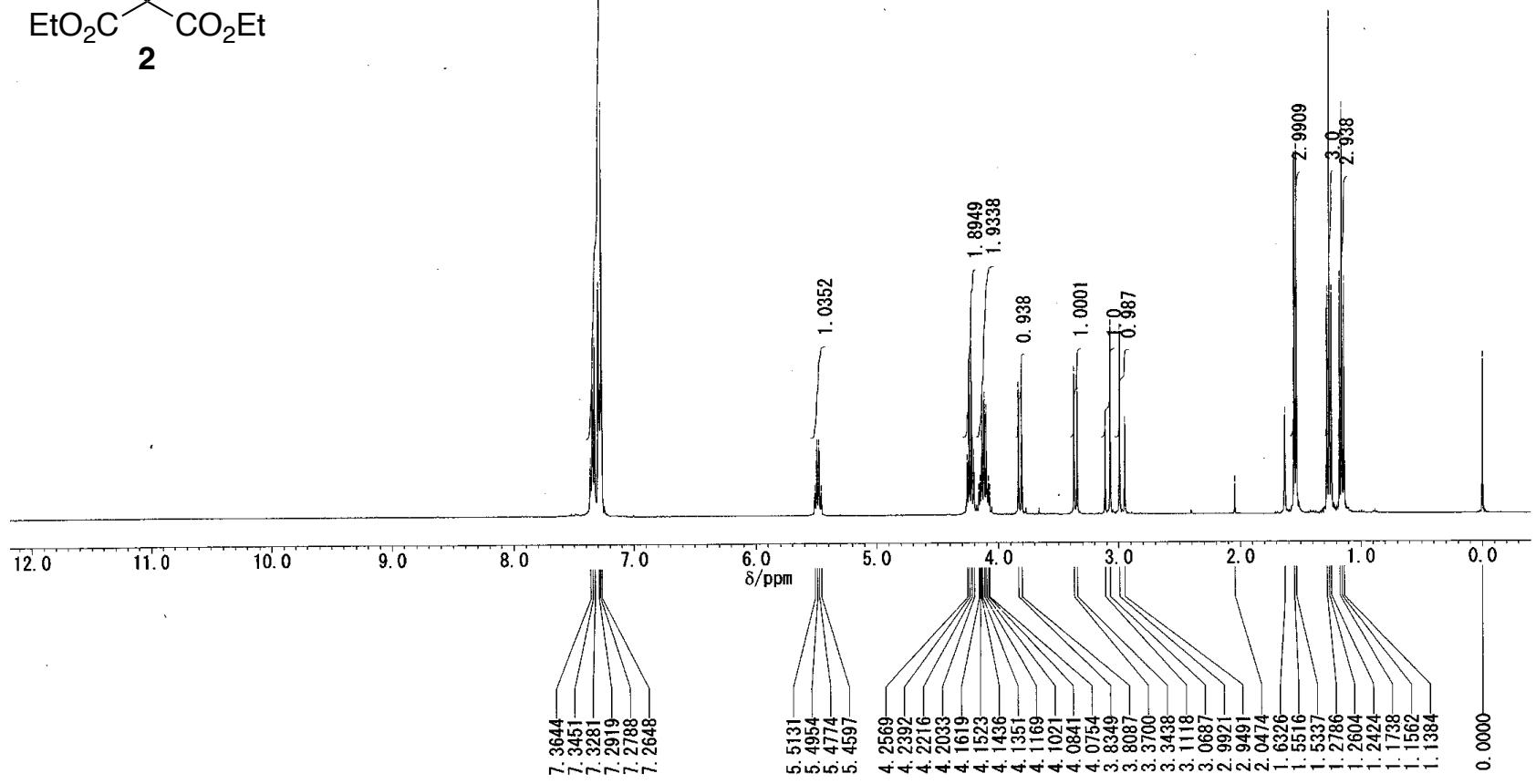

${ }^{13} \mathrm{C}$ NMR spectrum of $2\left(100 \mathrm{MHz}\right.$ in $\left.\mathrm{CDCl}_{3}\right)$<smiles></smiles>

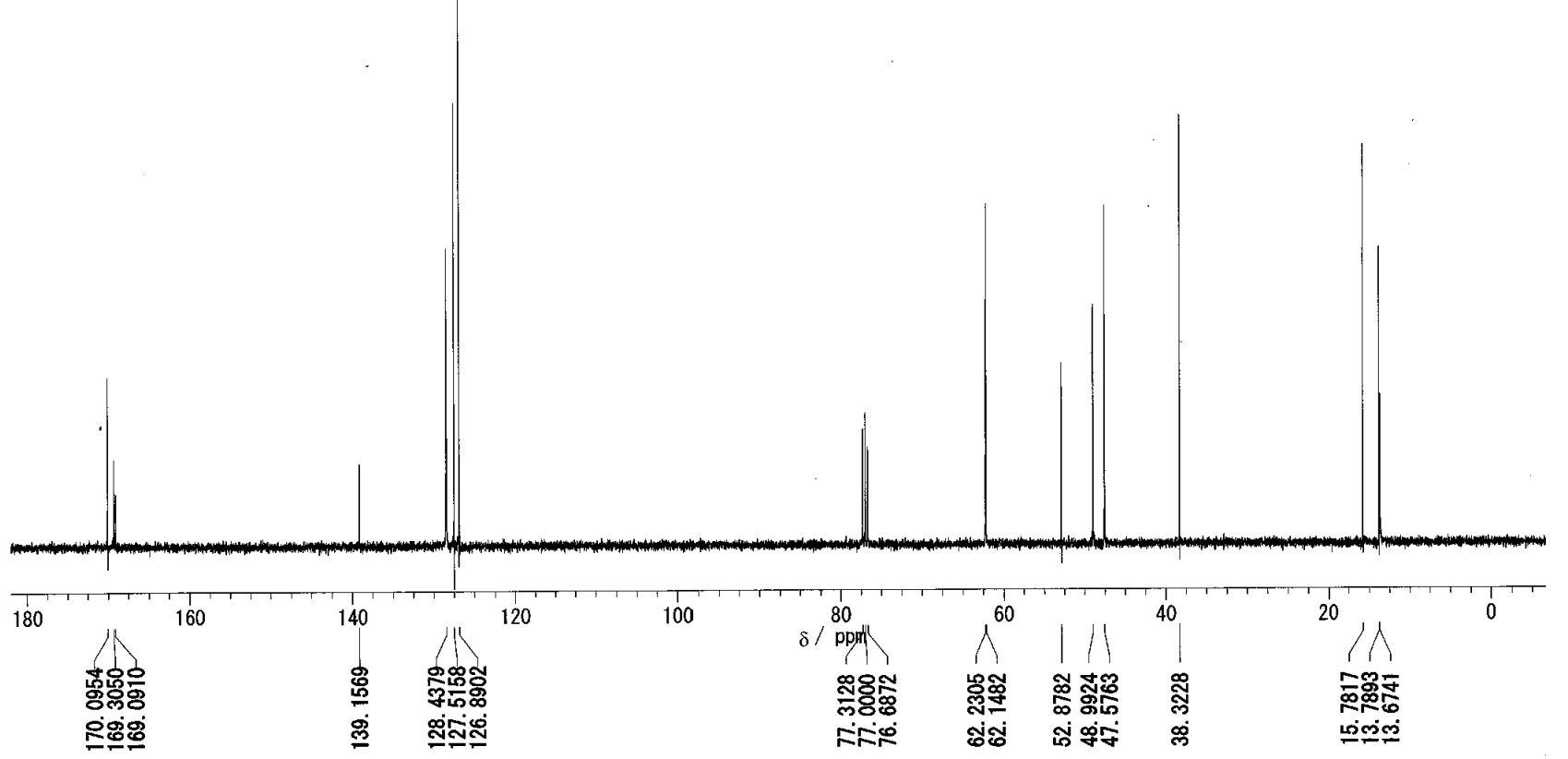


${ }^{1} \mathrm{H}$ NMR spectrum of $3\left(400 \mathrm{MHz}\right.$ in $\left.\mathrm{CDCl}_{3}\right)$<smiles>CCOC(=O)[C@]1(C(=O)O)CC(=O)N([C@H](C)c2ccccc2)C1</smiles>

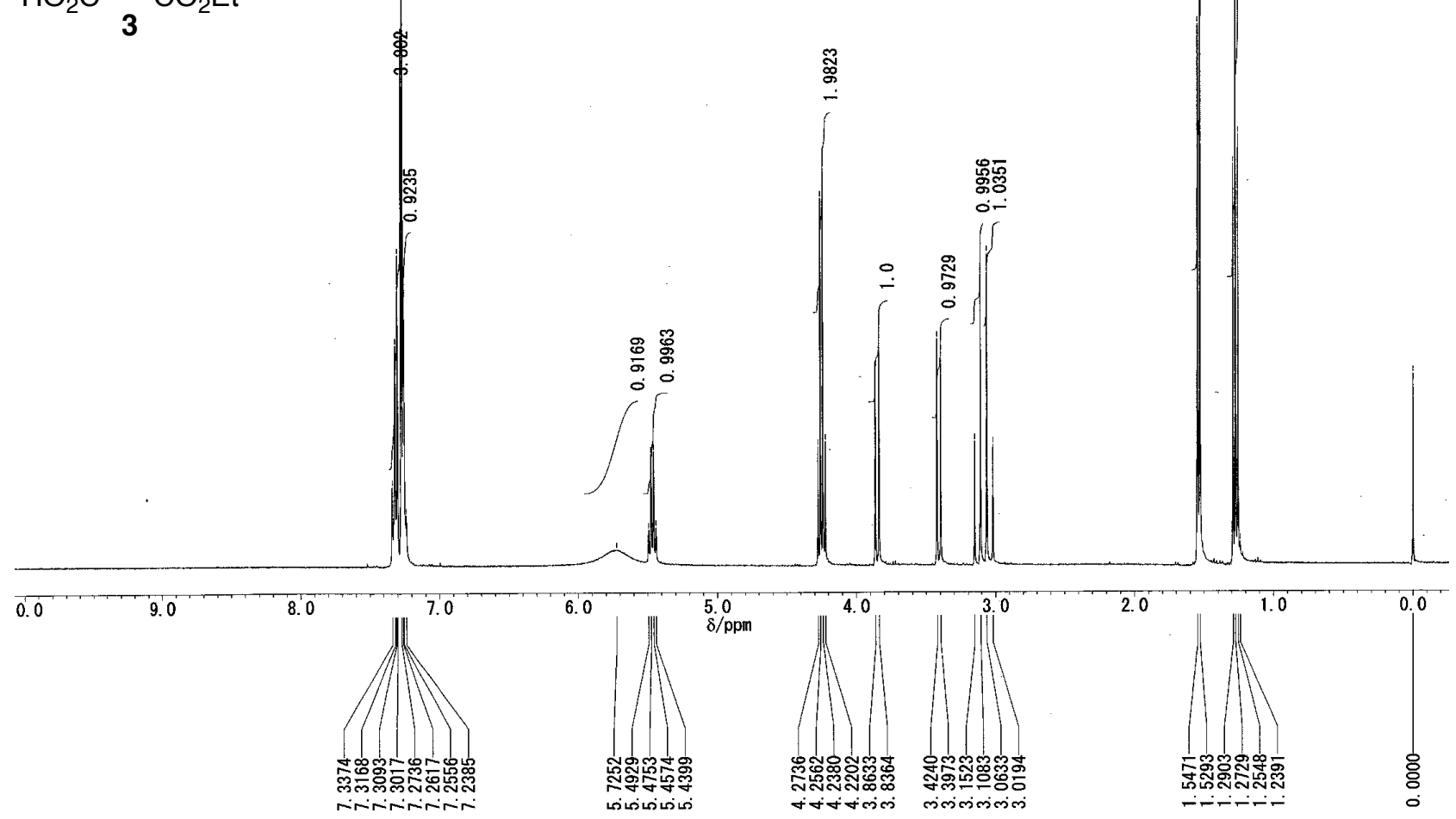

${ }^{13} \mathrm{C}$ NMR spectrum of 3 (100 MHz in DMSO-d6)<smiles></smiles>

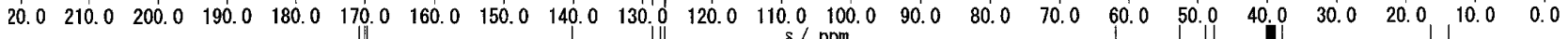

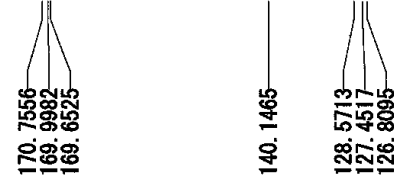
$\delta / \mathrm{ppm}$

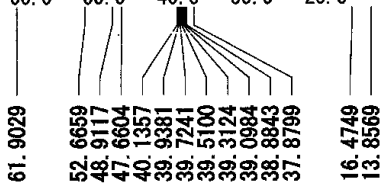


${ }^{1} \mathrm{H}$ NMR spectrum of $4\left(400 \mathrm{MHz}\right.$ in $\left.\mathrm{CDCl}_{3}\right)$

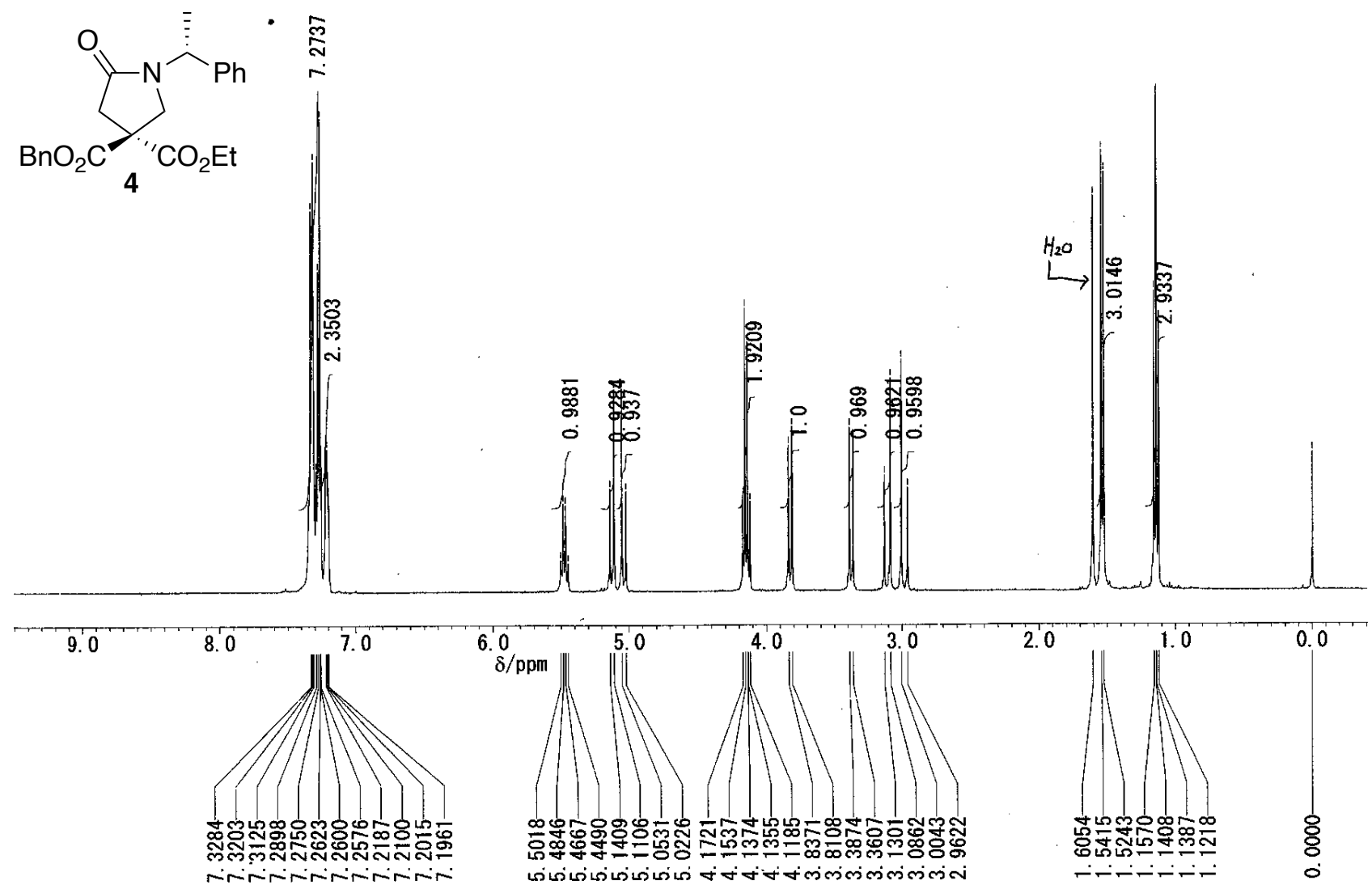

${ }^{13} \mathrm{C}$ NMR spectrum of $4\left(100 \mathrm{MHz}\right.$ in $\left.\mathrm{CDCl}_{3}\right)$<smiles>CCO[C@]1(C(=O)OCc2ccccc2)CC(=O)N([C@@H](C)c2ccccc2)C1</smiles>

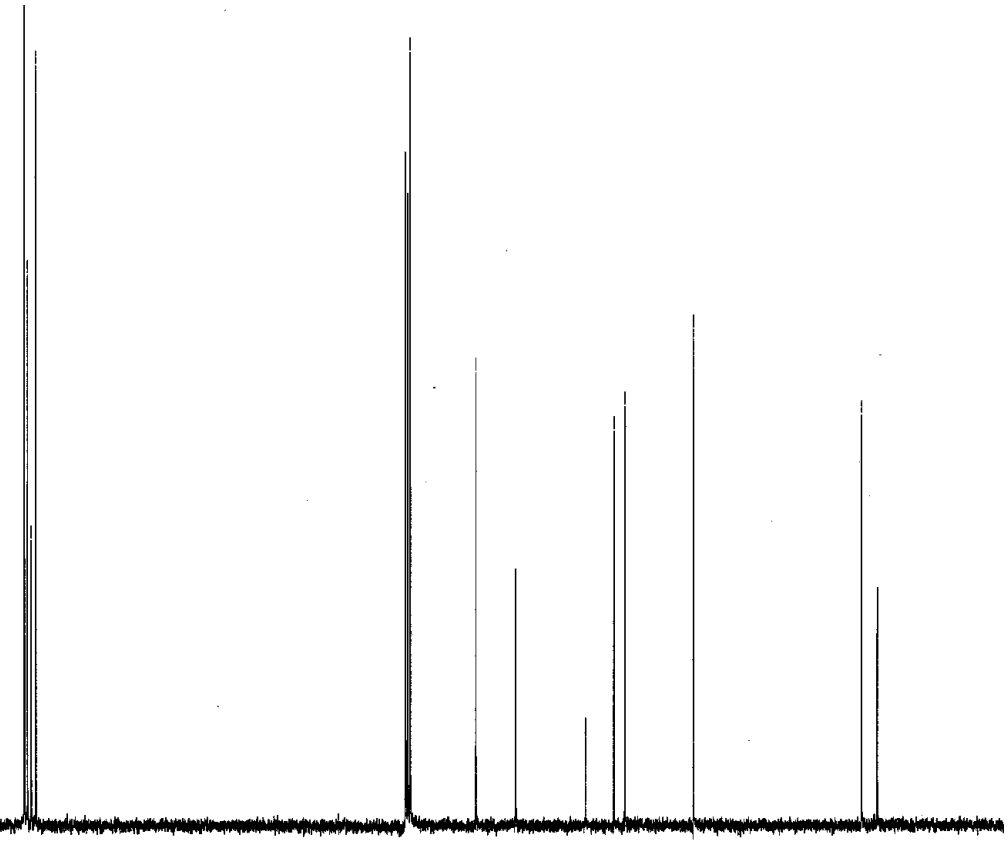

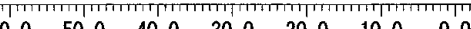

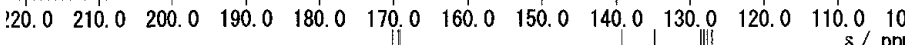
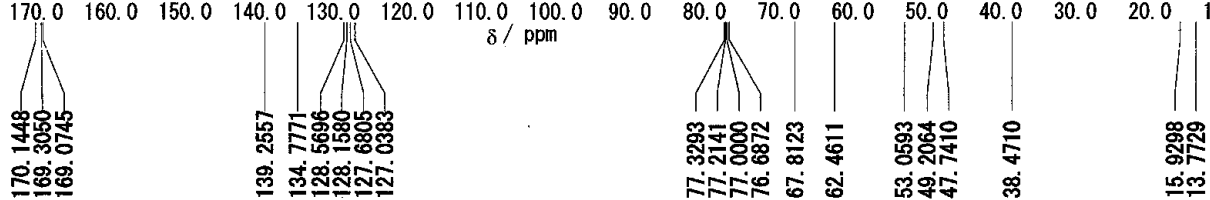
${ }^{1} \mathrm{H}$ NMR spectrum of $5\left(400 \mathrm{MHz}\right.$ in $\left.\mathrm{CDCl}_{3}\right)$
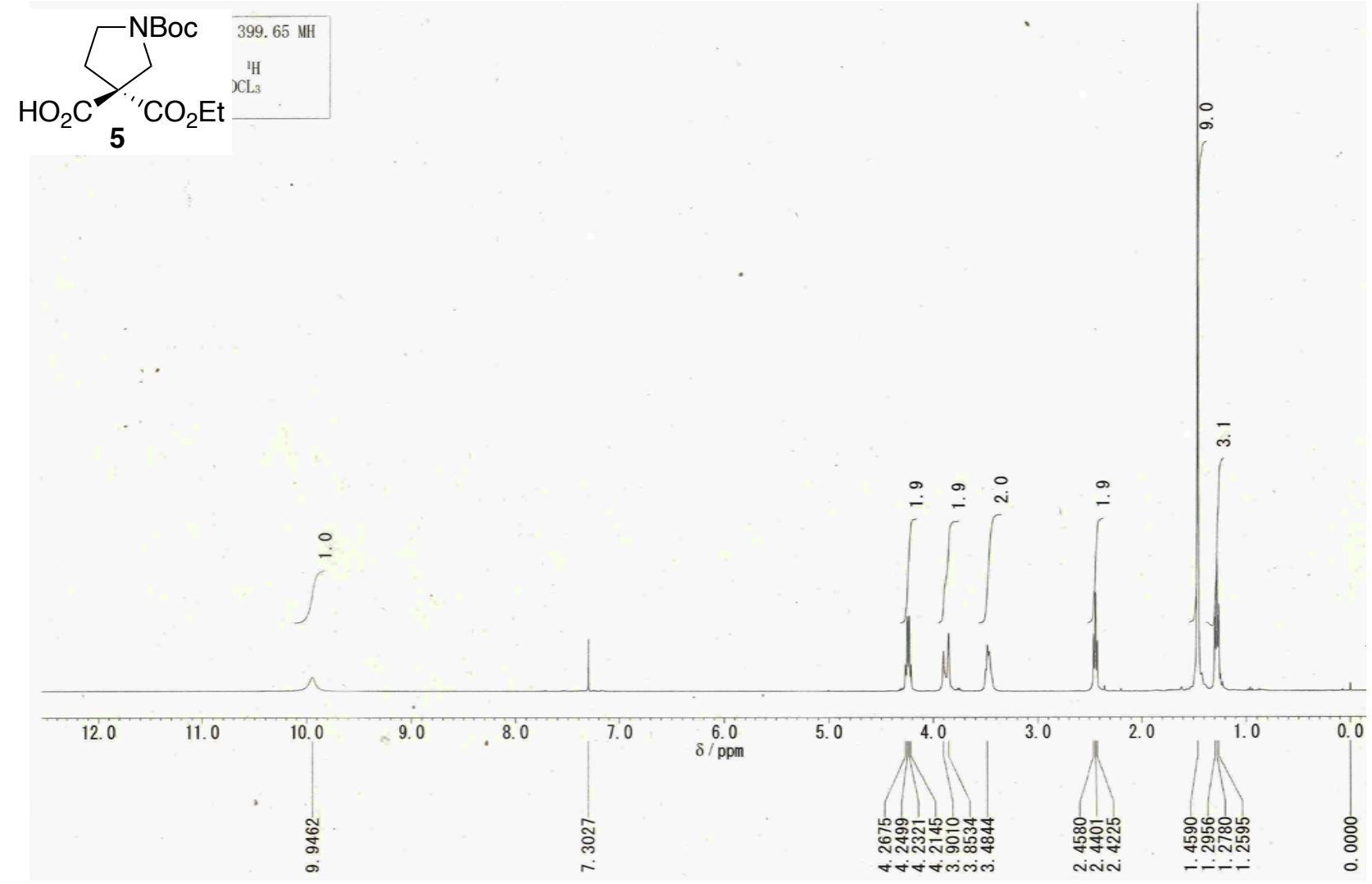

${ }^{13} \mathrm{C}$ NMR spectrum of $5\left(125 \mathrm{MHz}\right.$ in $\left.\mathrm{CDCl}_{3}\right)$
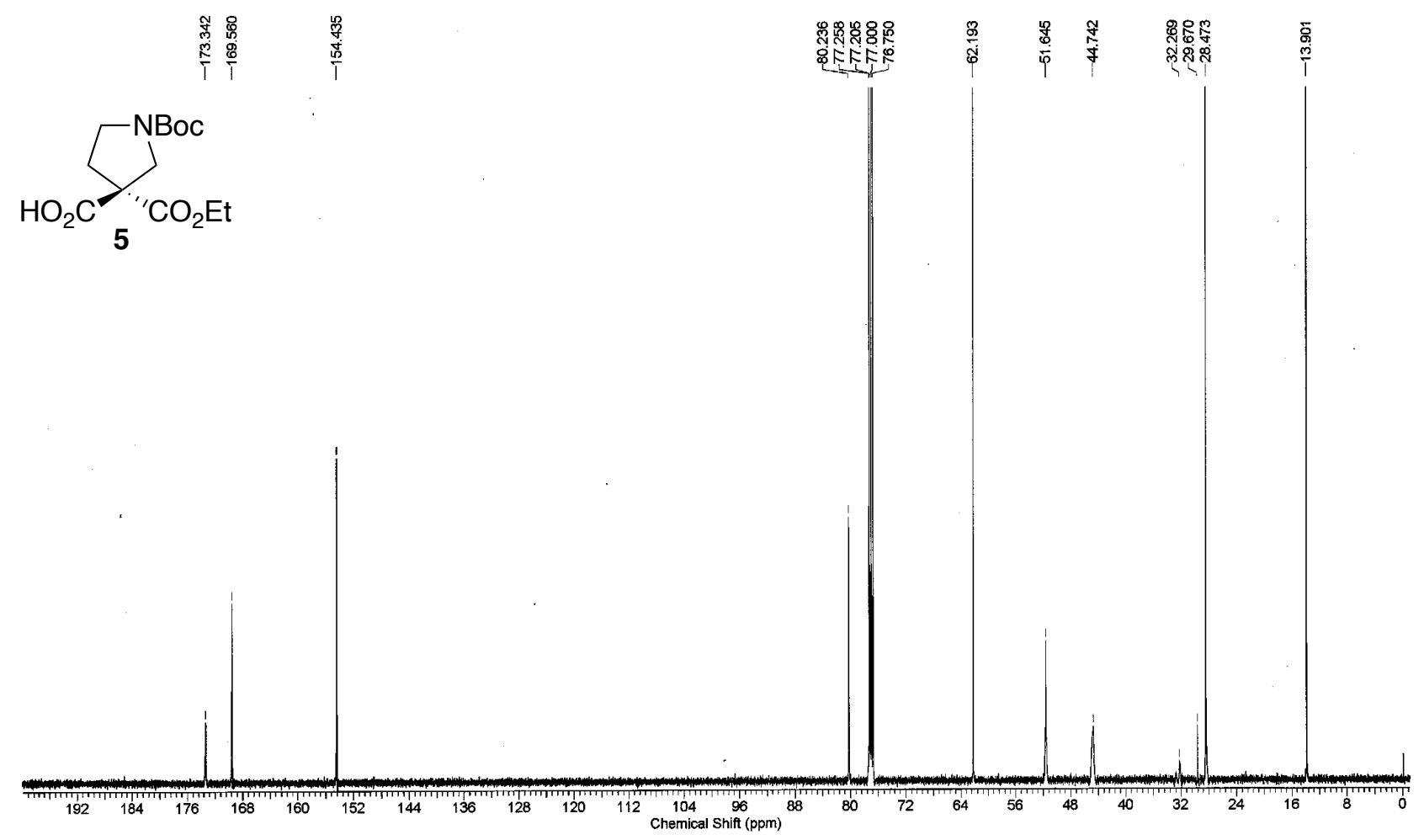
${ }^{1} \mathrm{H}$ NMR spectrum of $6\left(400 \mathrm{MHz}\right.$ in $\left.\mathrm{CDCl}_{3}\right)$
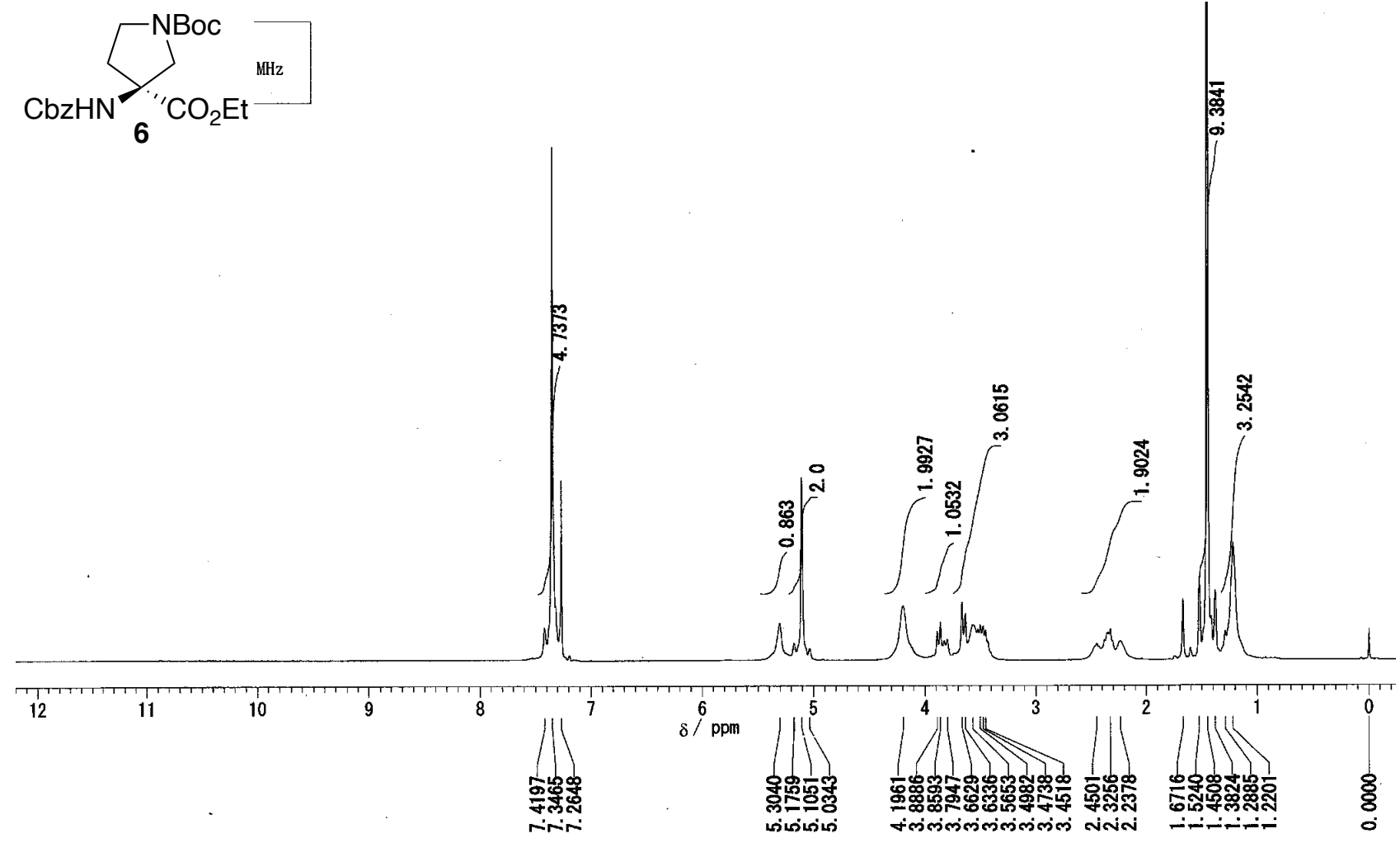

${ }^{13} \mathrm{C}$ NMR spectrum of $6\left(125 \mathrm{MHz}\right.$ in $\left.\mathrm{CDCl}_{3}\right)$

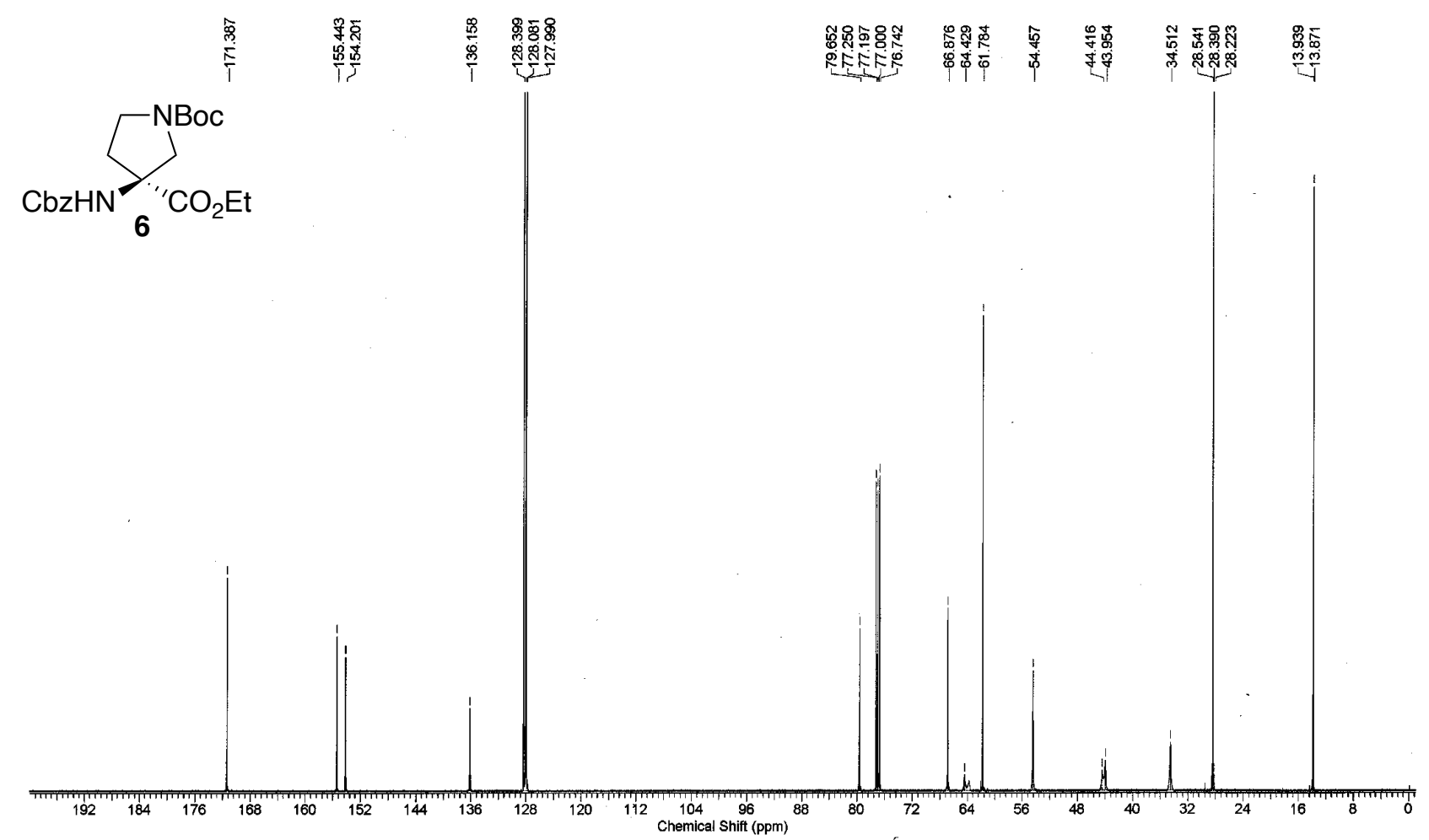


${ }^{1} \mathrm{H}$ NMR spectrum of $9\left(500 \mathrm{MHz}\right.$ in $\left.\mathrm{CD}_{3} \mathrm{CN}\right)$

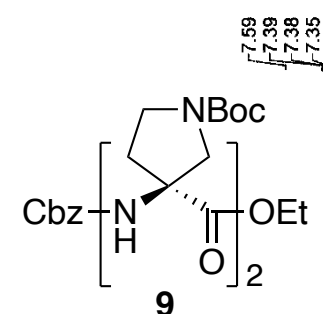

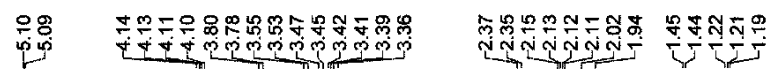

$\stackrel{\circ}{\varphi}$

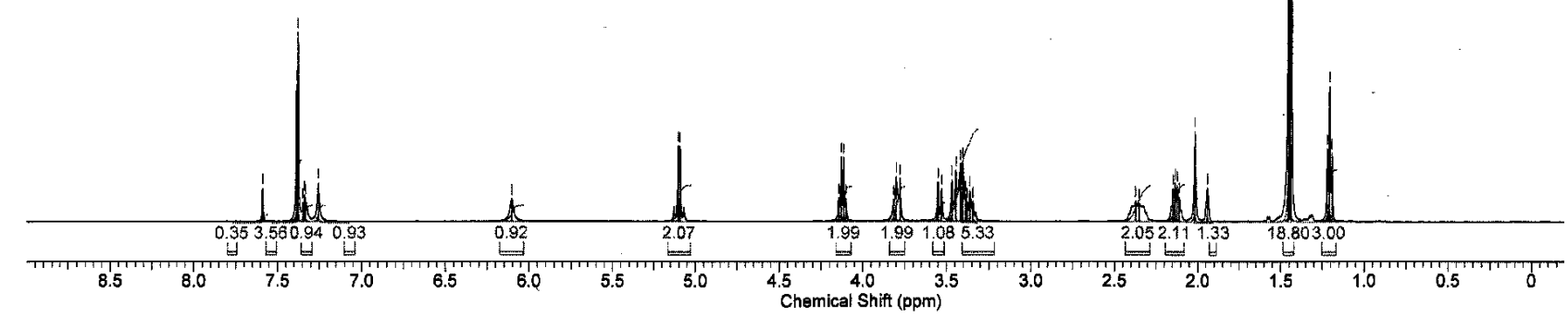

${ }^{13} \mathrm{C}$ NMR spectrum of 9 (125 $\mathrm{MHz}$ in $\left.\mathrm{CD}_{3} \mathrm{CN}\right)$

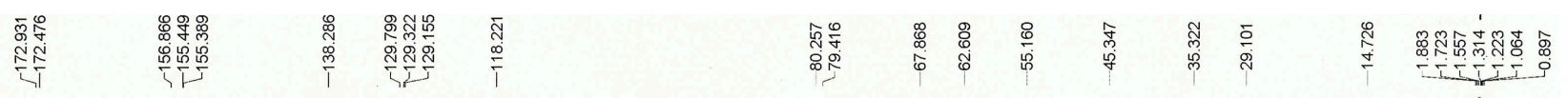<smiles>CCOC(=O)C1(NC(=O)CC)CCN(C(=O)OC(C)(C)C)CC1</smiles>

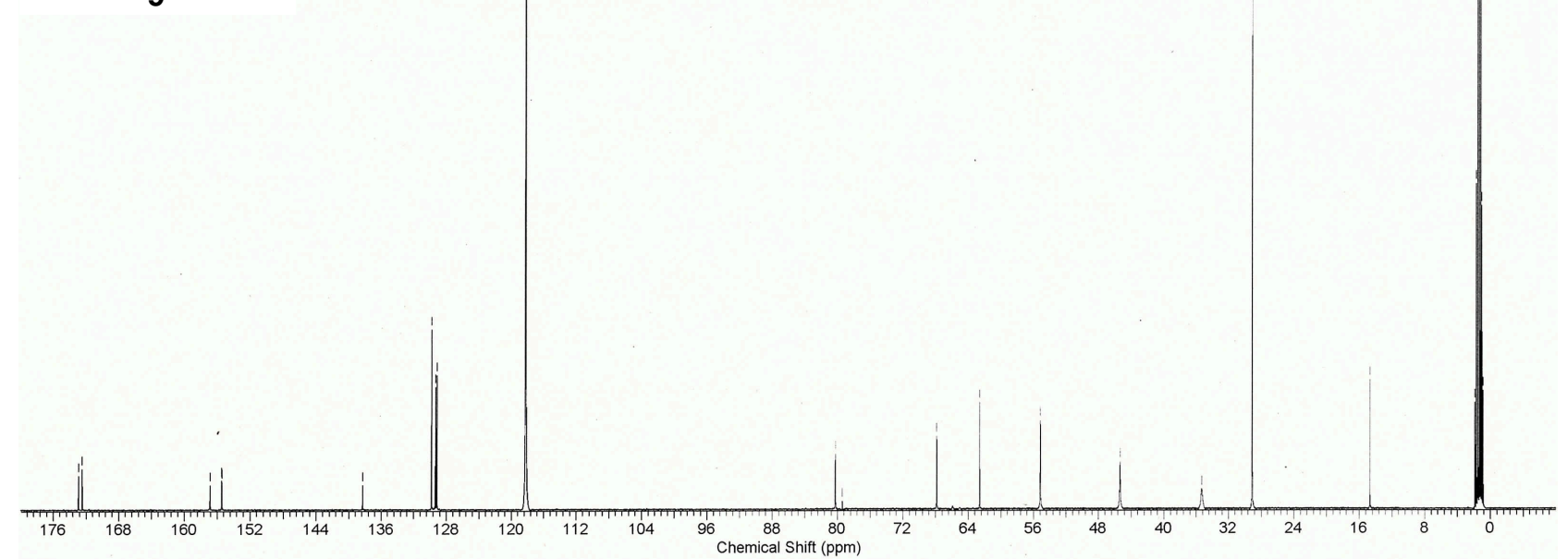


${ }^{1} \mathrm{H}$ NMR spectrum of $\mathbf{1 0}\left(500 \mathrm{MHz}\right.$ in $\left.\mathrm{CD}_{3} \mathrm{CN}\right)$

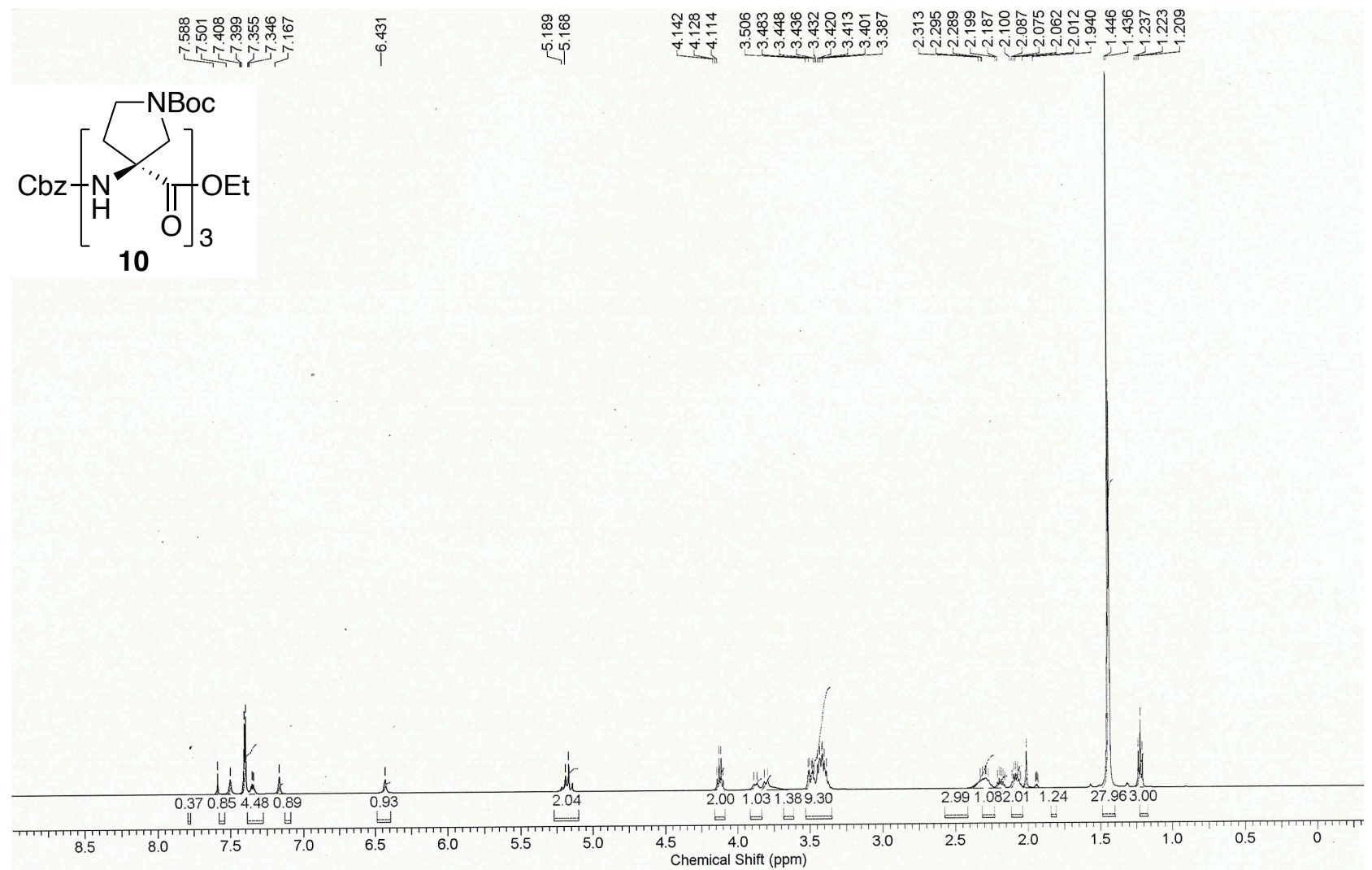

${ }^{13} \mathrm{C}$ NMR spectrum of $\mathbf{1 0}\left(125 \mathrm{MHz}\right.$ in $\left.\mathrm{CD}_{3} \mathrm{CN}\right)$

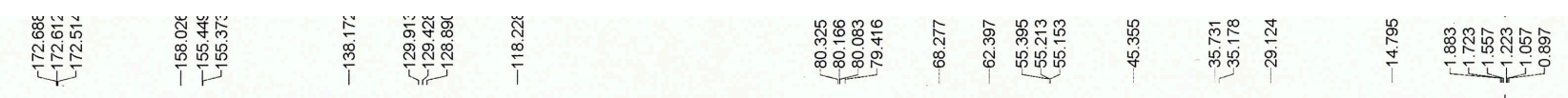<smiles>CCOC(=O)C1(C(=O)OC(C)(C)C)CCN(C(=O)OCc2ccccc2)CC1</smiles>

10
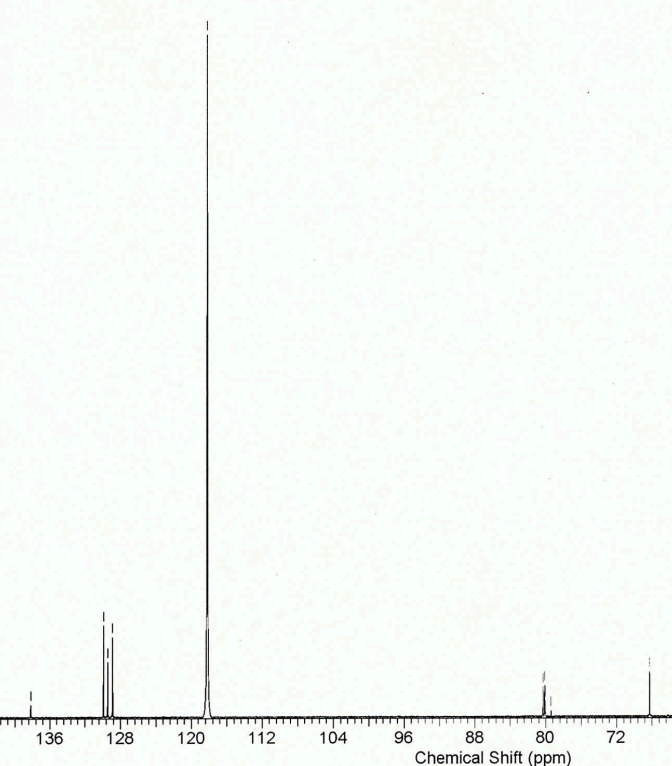
${ }^{1} \mathrm{H}$ NMR spectrum of $11\left(500 \mathrm{MHz}\right.$ in $\left.\mathrm{CD}_{3} \mathrm{CN}\right)$

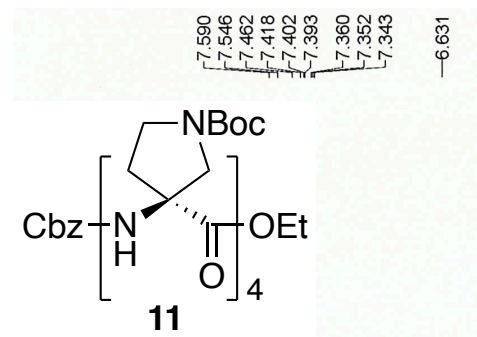

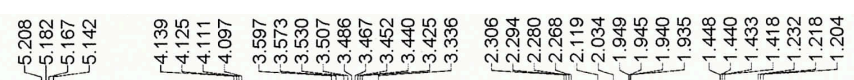

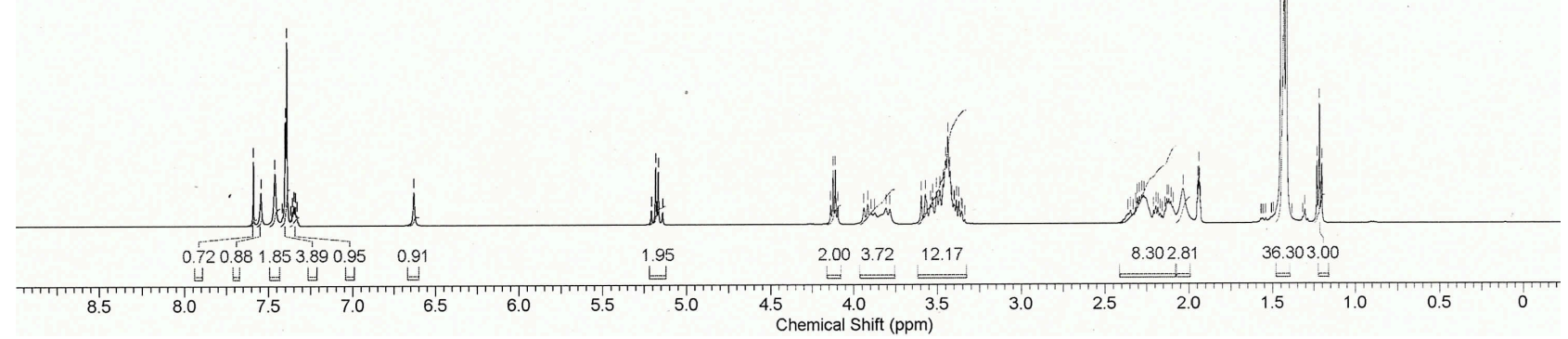

${ }^{13} \mathrm{C}$ NMR spectrum of $\mathbf{1 1}\left(125 \mathrm{MHz}\right.$ in $\left.\mathrm{CD}_{3} \mathrm{CN}\right)$

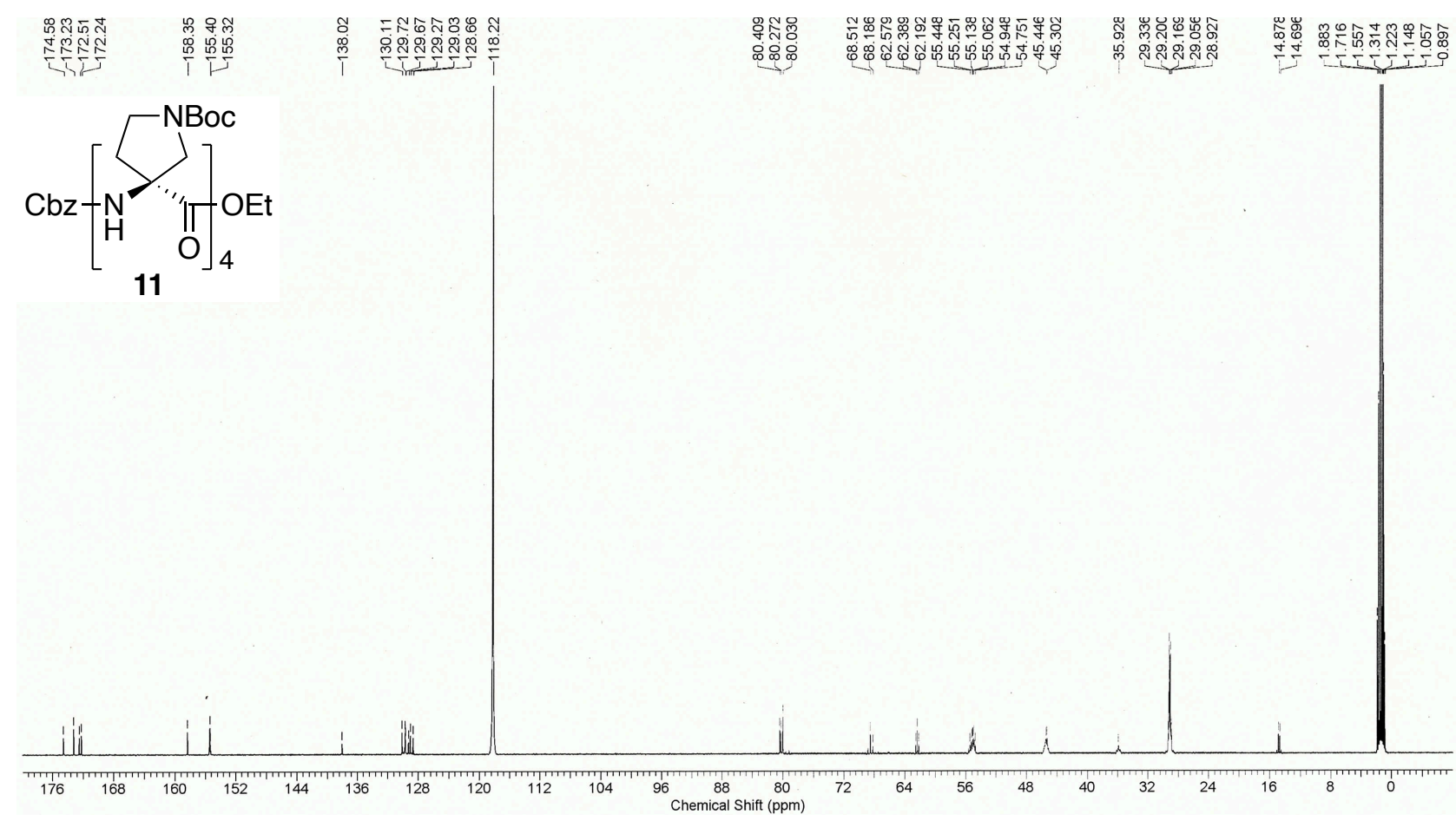


${ }^{1} \mathrm{H}$ NMR spectrum of $12\left(500 \mathrm{MHz}\right.$ in $\left.\mathrm{CD}_{3} \mathrm{CN}\right)$

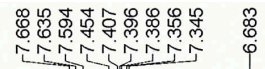

$\mathrm{Cbz}+\mathrm{N}_{\mathrm{H}}^{\mathrm{NBOC}}$

12
舟

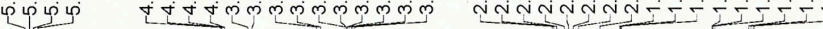

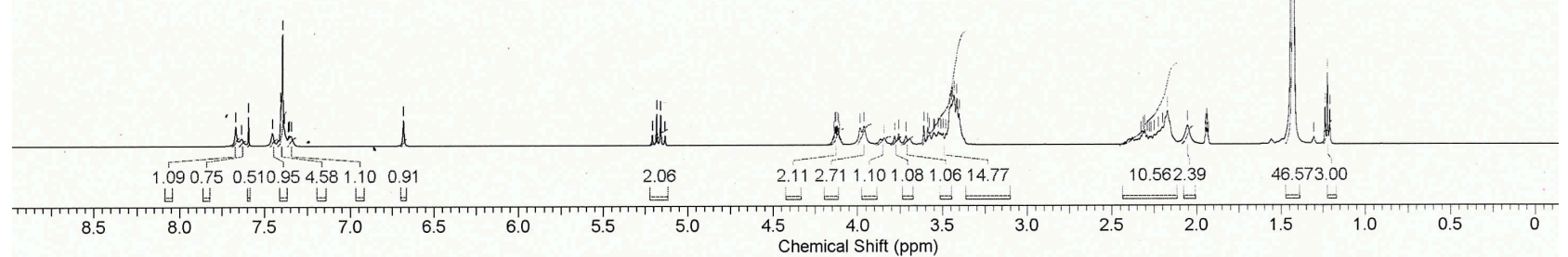

${ }^{13} \mathrm{C}$ NMR spectrum of $12\left(125 \mathrm{MHz}\right.$ in $\left.\mathrm{CD}_{3} \mathrm{CN}\right)$

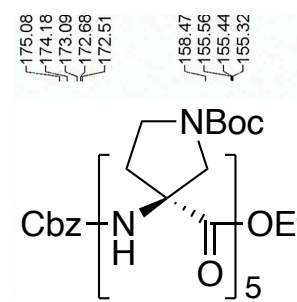

12

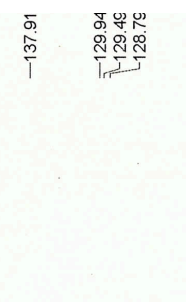

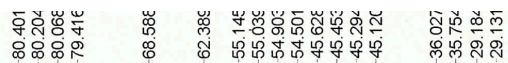

花

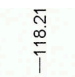

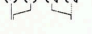
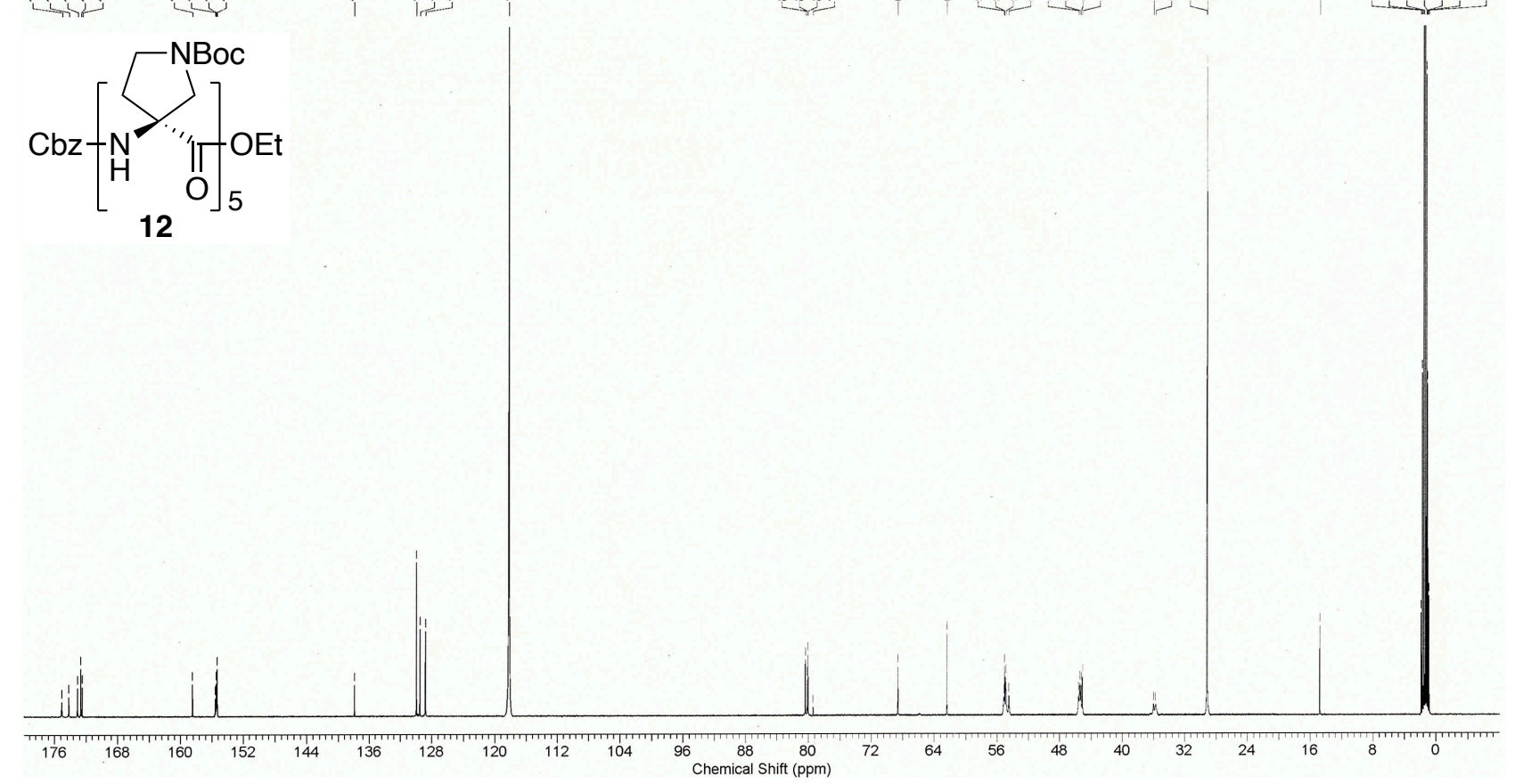
${ }^{1} \mathrm{H}$ NMR spectrum of $13\left(500 \mathrm{MHz}\right.$ in $\left.\mathrm{CD}_{3} \mathrm{CN}\right)$

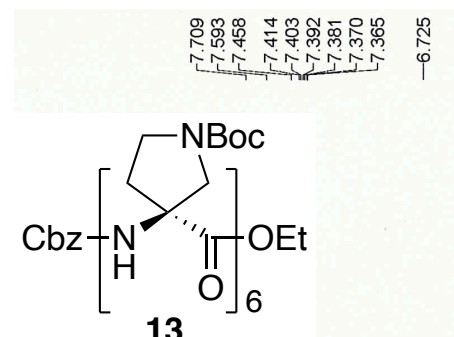

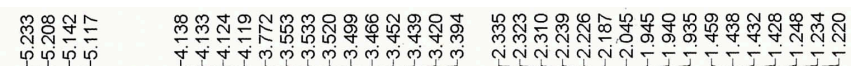

13

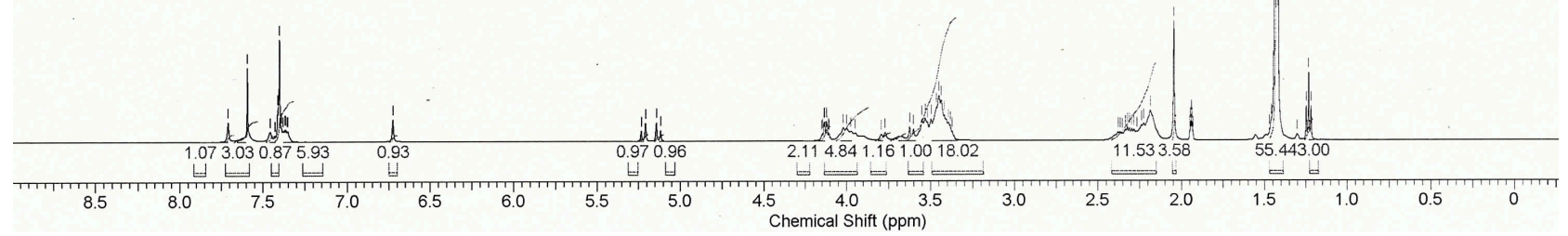

${ }^{13} \mathrm{C}$ NMR spectrum of $\mathbf{1 3}\left(125 \mathrm{MHz}\right.$ in $\left.\mathrm{CD}_{3} \mathrm{CN}\right)$

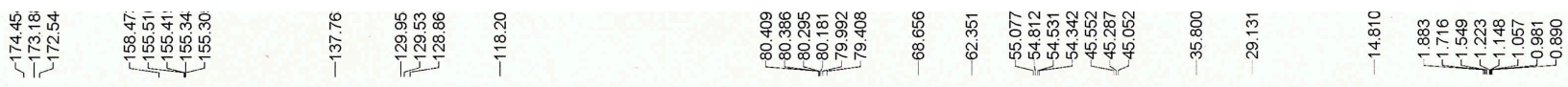<smiles>CCOC(=O)[C@@]1(NC(=O)[O-])CC[NH+](C(=O)OCc2ccccc2)C1</smiles>

13

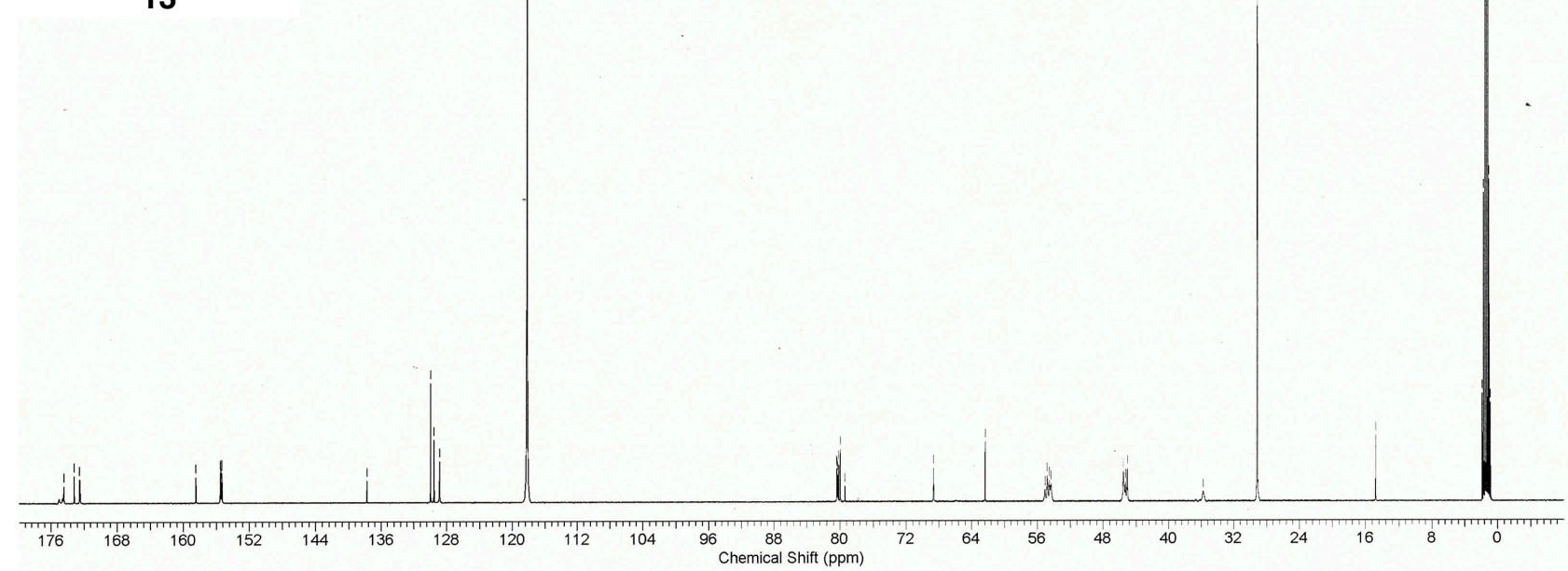


${ }^{1} \mathrm{H}$ NMR spectrum of $14\left(500 \mathrm{MHz}\right.$ in $\left.\mathrm{CD}_{3} \mathrm{CN}\right)$

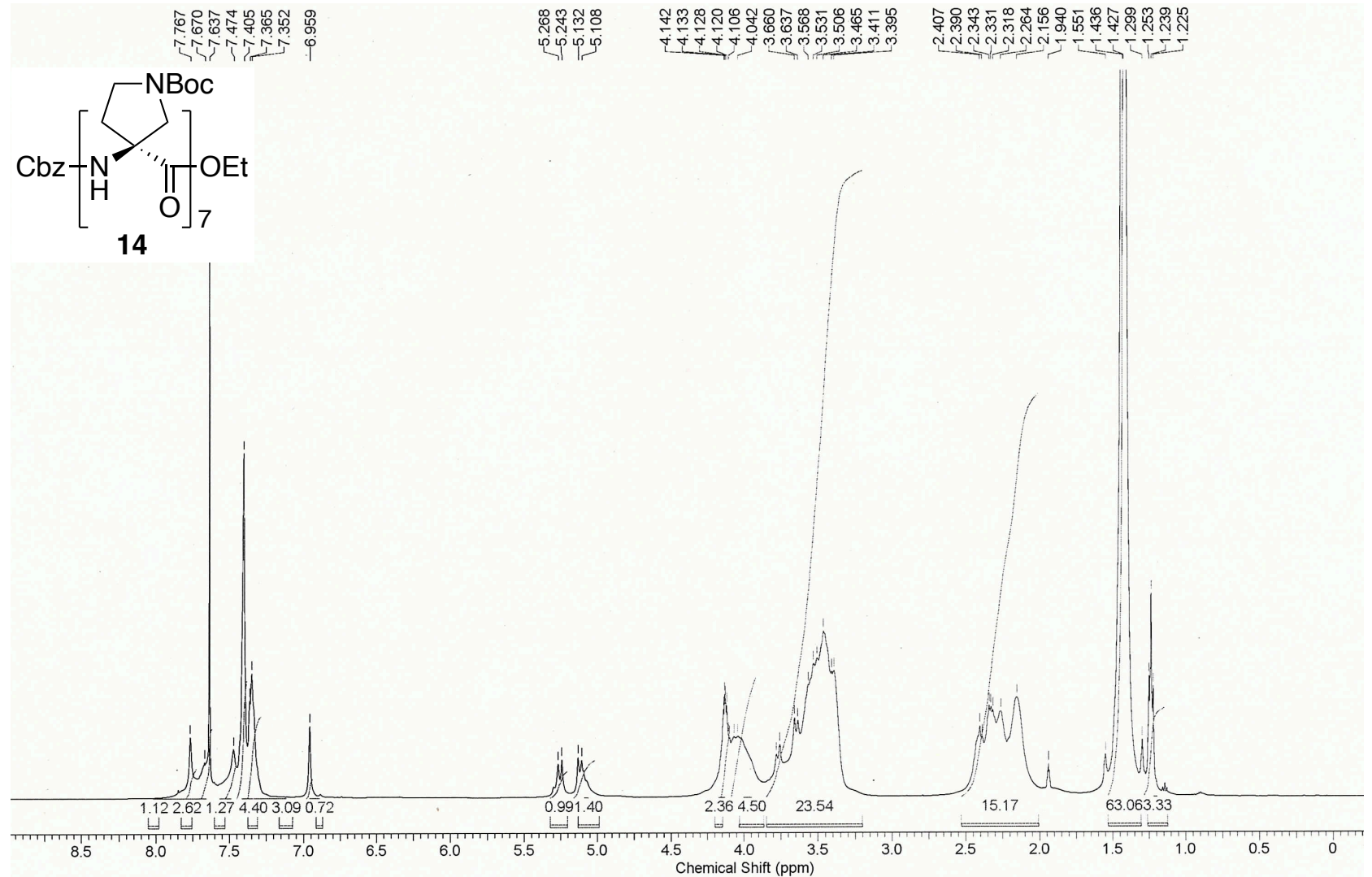

${ }^{13} \mathrm{C}$ NMR spectrum of $\mathbf{1 4}\left(125 \mathrm{MHz}\right.$ in $\left.\mathrm{CD}_{3} \mathrm{CN}\right)$
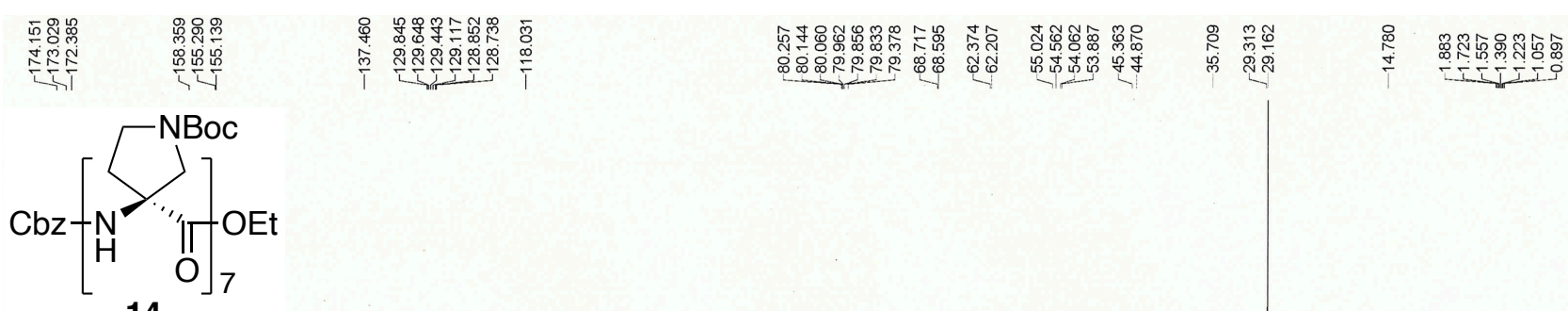

14

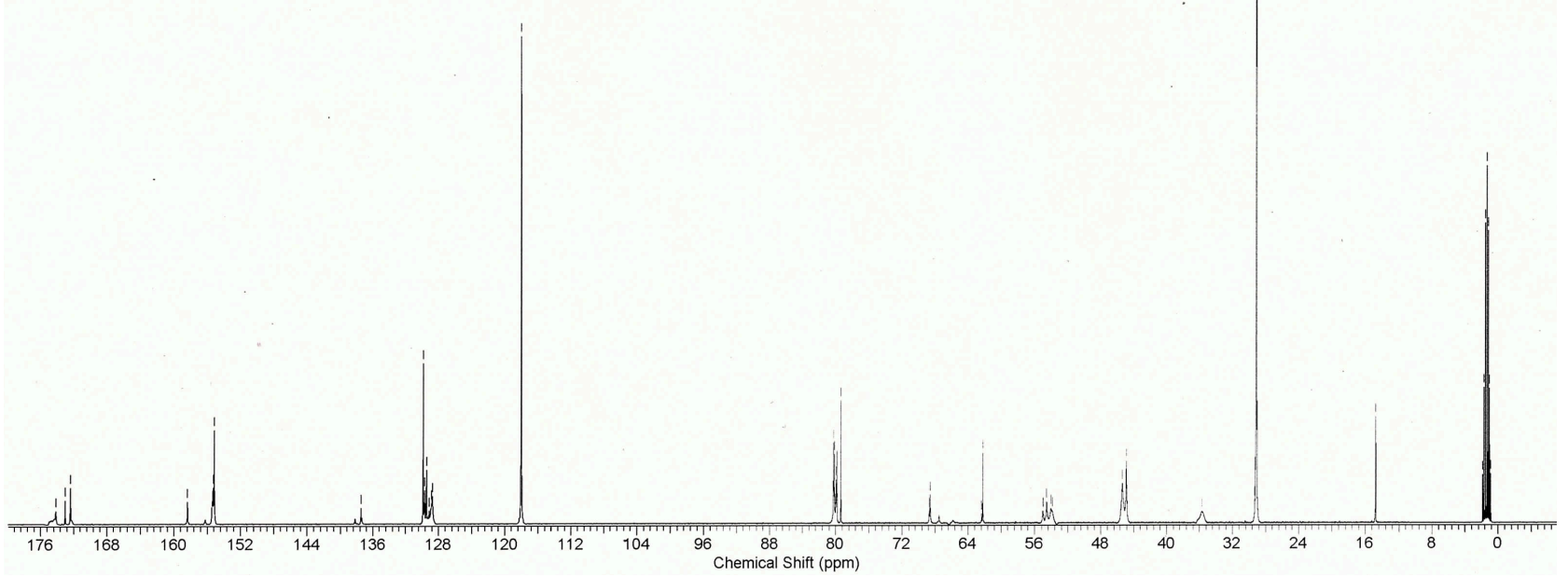


${ }^{1} \mathrm{H}$ NMR spectrum of $15\left(500 \mathrm{MHz}\right.$ in $\left.\mathrm{CD}_{3} \mathrm{CN}\right)$
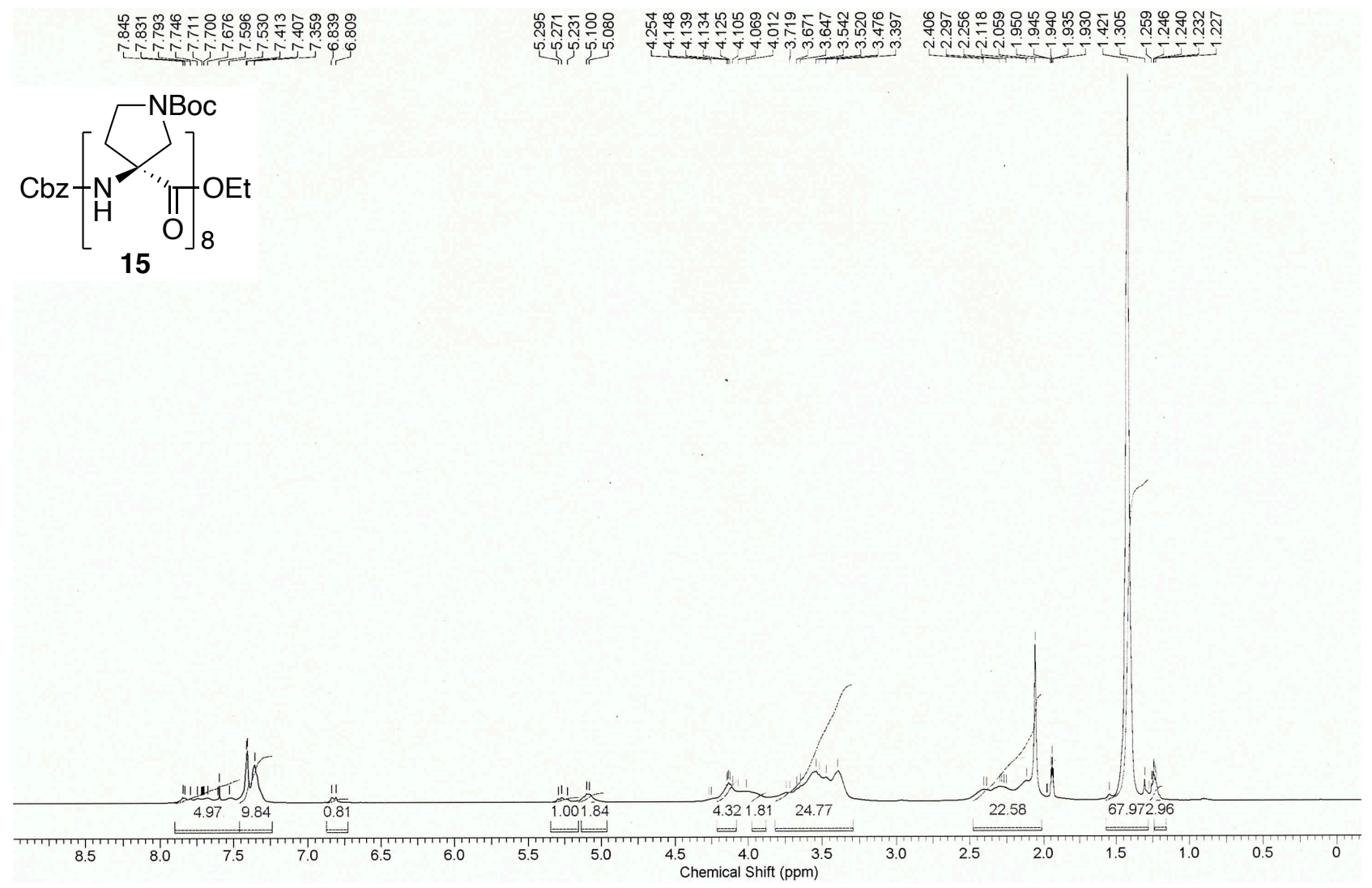

${ }^{13} \mathrm{C}$ NMR spectrum of $15\left(125 \mathrm{MHz}\right.$ in $\left.\mathrm{CD}_{3} \mathrm{CN}\right)$

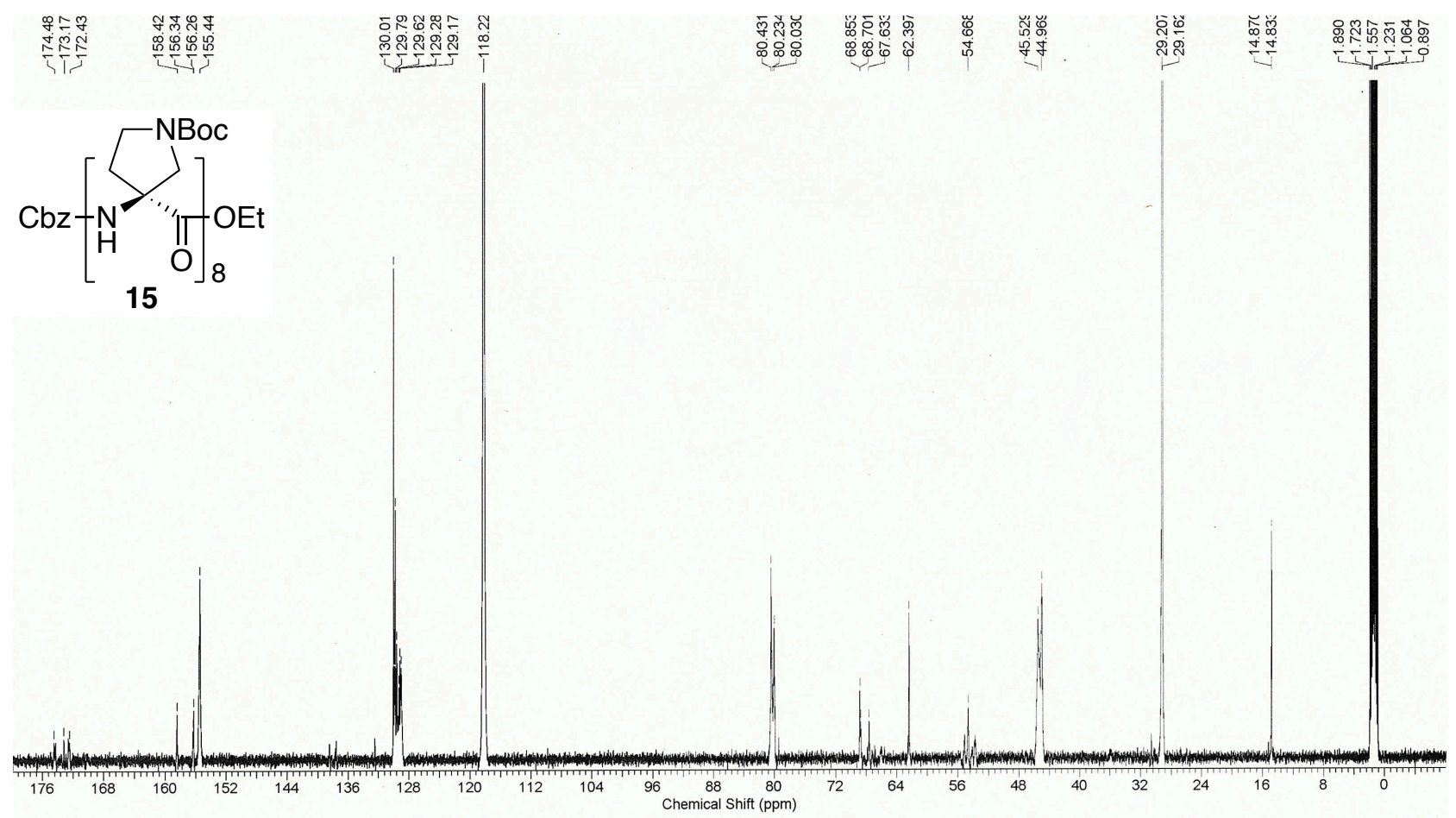


${ }^{1} \mathrm{H}$ NMR spectrum of 16 (500 MHz in $\left.\mathrm{CD}_{3} \mathrm{OH}\right)$

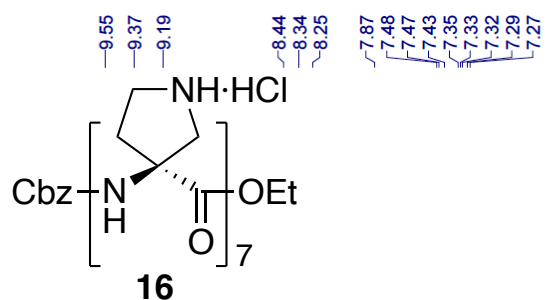

空

16

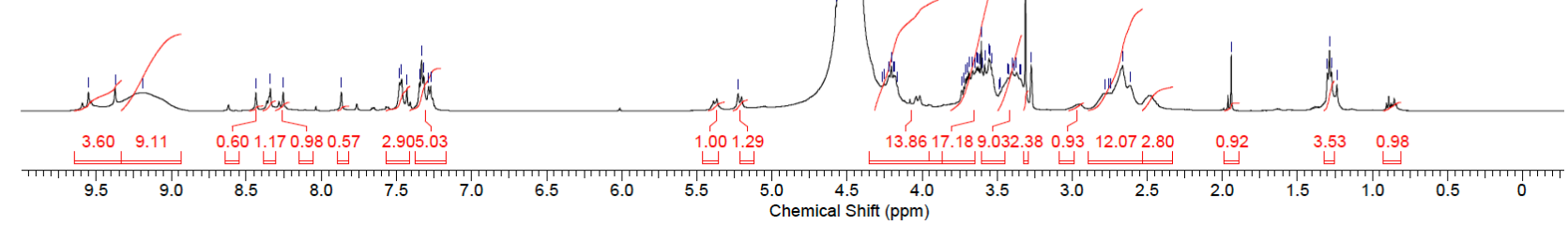

${ }^{13} \mathrm{C}$ NMR spectrum of $16\left(125 \mathrm{MHz}\right.$ in $\left.\mathrm{CD}_{3} \mathrm{OD}\right)$

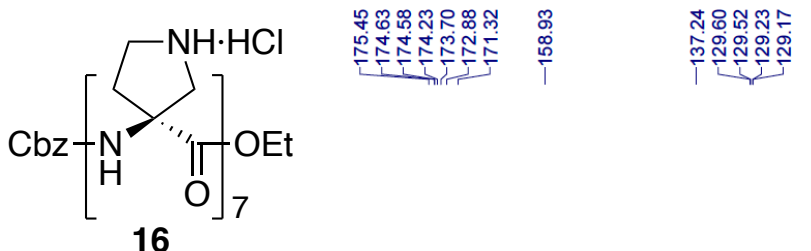

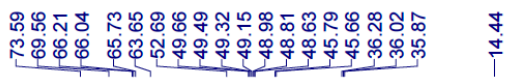

16

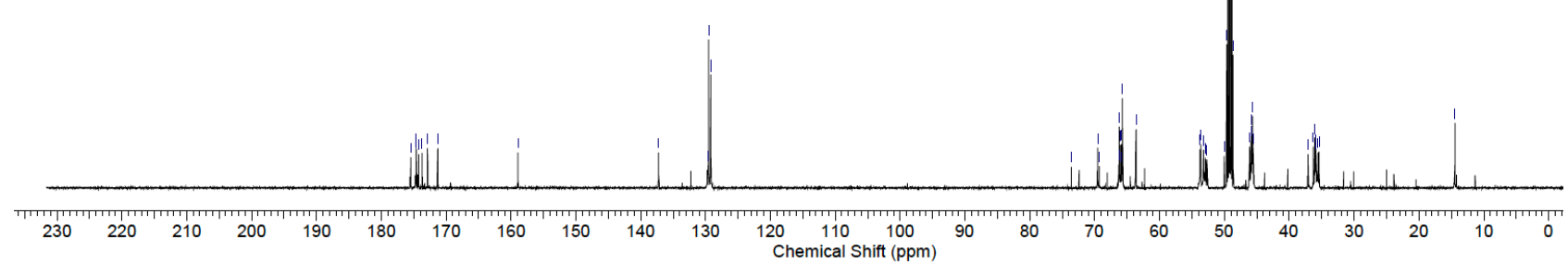


${ }^{1} \mathrm{H}$ NMR spectrum of $17\left(500 \mathrm{MHz}\right.$ in $\left.\mathrm{CD}_{3} \mathrm{OD}\right)$<smiles>CCOC(=O)[C@@]1(NC(=O)CN2CCCC2)CCNC1</smiles>

17<smiles>[14CH3]</smiles>

ए广

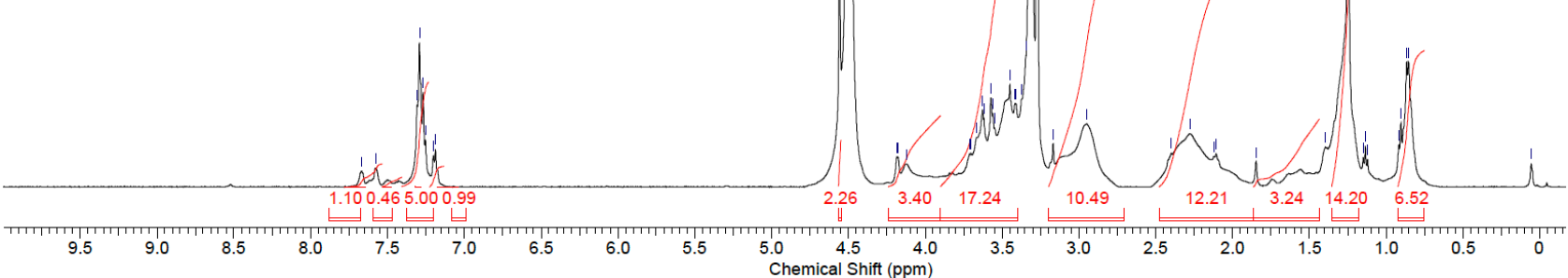

${ }^{13} \mathrm{C}$ NMR spectrum of $17\left(125 \mathrm{MHz}\right.$ in $\left.\mathrm{CD}_{3} \mathrm{OD}\right)$

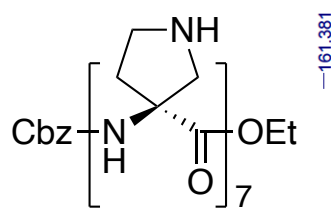

17

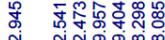

年

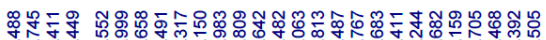

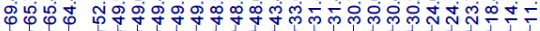

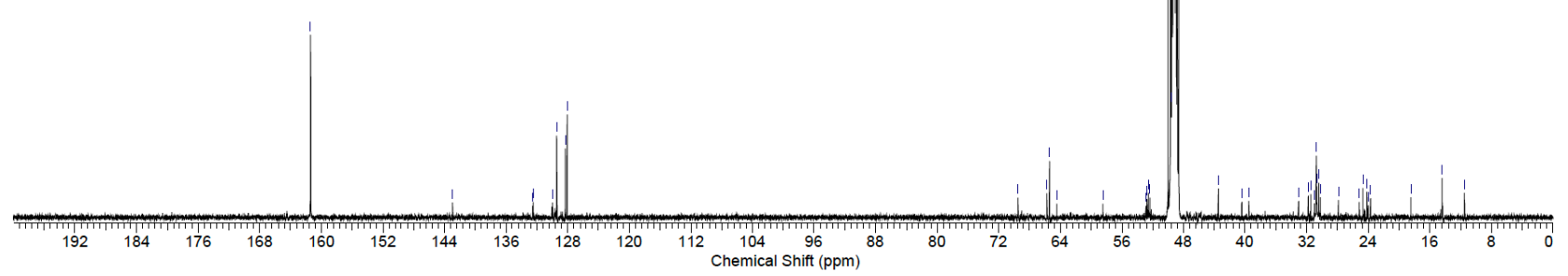

